\title{
Advances in Studies of the Thermosphere and Ionosphere during the Next Decade
}

\author{
David ReES \\ Atmospheric Physics Laboratory, University College London, \\ 67-73 Riding House Street, London WIP 7PP, UK.
}

(Received November 17, 1990; Revised March 18, 1991)

\begin{abstract}
During the past decade, with few new space opportunities, many studies of the thermosphere and ionosphere have utilised data obtained from networks of groundbased instruments, interpreted with the aid of advanced theoretical and numerical models. These current methods have limitations. The thermosphere and ionosphere respond to inputs of varying spatial and temporal scales. There are global-scale energy inputs from solar UV and EUV radiation. Energy and momentum inputs from the magnetosphere are related to the mapping of the auroral ovals onto the thermosphere and ionosphere. The inputs to the thermosphere and ionosphere from the lower atmosphere have components of all scales, from the global distribution of propagating tides and planetary waves, to gravity waves which are generally thought to have intense and generally localised origins. The capabilities of some potential new techniques will also be surveyed in this review. Within the next decade, it will be possible to obtain time-sequences of large-scale images of the most important parameters and velocity flows of the thermosphere and ionosphere from space-borne instruments. Data from these new space-borne instruments will be combined with that from conventional space-borne instruments, from upgraded networks of groundbased radar and optical instruments, and from space-borne and ground-based monitors of solar and magnetospheric energy and momentum inputs. Greatly improved numerical modelling tools will also become available to aid evaluation and interpretation of these new observational data, including improved techniques for the assimilation of fragmentary observations. Recent achievements will be reviewed, and the scientific requirements for addressing the outstanding scientific problems concerning coupling between the magnetosphere, thermosphere and ionosphere and the lower and middle atmosphere.
\end{abstract}

\section{Background and Introduction}

The thermosphere and ionosphere respond with varying spatial and temporal-scales to inputs of energy and momentum from the sun and lower atmosphere, and to the mainly highlatitude momentum and energy inputs from the magnetosphere. In global terms, the most powerful energy source for the thermosphere and ionosphere is solar UV and EUV radiation, absorbed within the thermospheric region. Absorption of solar UV and EUV radiation involves a wide range of aeronomic processes:- heating, photo-dissociation, photoionisation, excitation of atoms and molecules, and the subsequent neutral and ionic recombination processes. These have all been well studied by theory, observation and laboratory simulation, although some important uncertainties still remain. However, the 
solar UV and EUV spectrum is highly variable, depending on solar phenomena or "weather". While certain of the relationships between the solar spectrum variations and the underlying solar phenomena are well understood, the solar UV/EUV spectrum is not routinely monitored. The aeronomic input of solar radiation to atmospheric and ionospheric models thus relies on a parameterisation of "solar activity", keyed to an available index such as the solar radio flux (F $10.7 \mathrm{~cm}$ ) or the "sunspot number". While these indexed inputs are probably acceptable for "mean" studies, they still leave a great deal to be desired for studies of specific events. The long-term solution is data obtained from a continuously-available and inter-calibrated space-borne solar UV/EUV monitor, however, such an instrument is still not a firm part of any space programme.

Compared with the total solar constant, the proportion of solar energy which is directly absorbed in the mesosphere and thermosphere is quite modest (of the order of $0.1 \%$ ). The bulk of the solar radiation reaches the lower atmosphere or surface, undergoing a complex sequence of processes involving the oceans, icecaps, the hydrological cycle, and radiative transfer within the near-surface, tropospheric and stratospheric regions. As far as the mesosphere, lower thermosphere and ionosphere are concerned, significant energetic and dynamical effects occur as the result of solar heating within the lower atmosphere, generating the combination of tidal waves, gravity waves and planetary waves. The propagation of these waves and tides through the lower and middle atmosphere is complex. Large non-linear interactions occur between the individual propagating tidal modes themselves, and between them, the planetary and gravity waves and the tides generated in-situ within the thermosphere by solar UV and EUV heating. The dissipation of some of the upwelling wave energy represents a significant fraction of the total energy budget of the mesosphere and lower thermosphere. Progress in understanding the meteorology and climatology of the upper mesosphere and lower thermosphere has been extremely slow, and the provision of observation data on the time-dependent structure, composition and dynamics of these region for the entire globe is still a long-term dream.

At all times and at all geomagnetic activity levels, the magnetosphere imprints unmistakable signatures upon the high-latitude thermosphere and ionosphere. The globallyintegrated magnetospheric energy input (primarily Joule heating in the auroral electrojets and particle heating from auroral electron precipitation) to the thermosphere and ionosphere is usually much less than the solar UV and EUV energy input. However, the deposition of magnetospheric energy is mainly "focussed" onto localised high-latitude regions- the auroral ovals. There, the local energy deposition rates, even from the quiescent magnetosphere, usually considerably exceeds the average globally-integrated solar UV and EUV heating rate. At times of extreme magnetospheric disturbances, the local heating rate in the height region above about $110 \mathrm{~km}$ can exceed the average solar heating of the equivalent region by a factor approaching 1000. At such times, the total globally-integrated global magnetospheric input to the thermosphere may exceed the total globally-integrated solar UV and EUV inputs.

Recent observations from satellites and from new polar ground-based observatories have shown the ionospheric structures, and thermospheric density, temperature, composition and winds are persistently disturbed in the vicinity of the auroral oval and within the geomagnetic polar cap. When the magnetosphere is in a "quiescent" state, the region of such imprints recede poleward, away from areas of significant population, and thus historical observations. These disturbances are always co-located with signatures of energetic particle precipitation and associated magnetospheric convective electric fields, which induce both the ionosphere and the thermosphere into rapid motion. Within both the thermosphere and ionosphere, however, 
some categories of disturbance, particularly thermospheric compositional disturbances and ionospheric $F$-region depletions, may be observed as the "fossils" previously created during periods of strong geomagnetic forcing.

Taking up the theme of obtaining a greatly improved understanding of the ionosphere, thermosphere and magnetosphere as highly dynamic, strongly interacting regions, a series of highly critical new measurements are required. Since we are concerned with these phenomena and interactions on a global scale, techniques which can provide large-scale images of the structure and the dynamics of atmosphere and ionosphere will be the most valuable. In the past decade, exciting advances have been made by the availability of images of the aurora and airglow, mapping magnetospheric electron precipitation. However, there are many other parameters which can be "imaged" from space. Among the most important targets for future space instruments and mission are: (1) Distributions of Ionospheric Plasma; (2) Distributions of Upper Mesospheric and Thermospheric Constituents; (3) Distribution of Energetic Magnetospheric Plasma; (4) The Polar Convective Electric Field Distribution; (5) The Global Neutral Wind System; (6) The Joule Heating Distribution; (7) The Ionospheric Current system; and (8) The Field-Aligned (Birkeland) Current System.

The order of priority in the above list reflects my own impression of the order in which experimental techniques can or will be devised and implemented to make the observations, rather than any innate scientific priority. The latter would, naturally, reflect individual interests and priorities. At present, several of these quantities can only by gleaned from calculations using empirical of theoretical numerical models, by assuming empirical models of the auroral electron precipitation distribution and the convective field.

It is not the intention of this review to describe exhaustively the new technologies required to develop suitable instruments. Some of the recently-demonstrated advances will be highlighted, indicating future requirements, particularly for future observations of highlatitude phenomena, where the ionosphere and thermosphere are under the strong influence of the magnetosphere.

\section{Recent Observational Results from the Ground and from Satellites}

\subsection{Scientific review}

As the magnetospheric state changes from a quiet to a very disturbed condition, the auroral oval generally expands equatorward and broadens, and the cross-polar cap electric field increases. This expansion and broadening of the auroral oval is accompanied by a corresponding intensification of auroral precipitation, well shown in statistical analyses of energetic electron precipitation (HARDY et al., 1985; FULLER-ROWELL and EVANS, 1987, Fig. 1). These statistical surveys complement the impression obtained from individual observations. Analyses of polar plasma convection (HEPPNER, 1977; HEPPNER and MAYNARD, 1987; FOSTER et al., 1986), also show that magnetospheric convection electric fields undergo a closely related equatorward expansion and intensification (also in Fig. 1) with increasing magnetospheric activity.

Above about $110 \mathrm{~km}$, the ions impart momentum to the neutral gas via collisions or "ion drag", losing part of their $\left(\underline{E}^{\wedge} \underline{B}\right)$ velocity (RISHBETH, 1972). The charge separation from the electron flow (essentially still the $\left(\underline{E}^{\wedge} \underline{B}\right)$ velocity) above $110 \mathrm{~km}$, creates the Pedersen ionospheric current component flowing parallel to $\underline{E}$. The Pedersen current flowing within the auroral ionosphere is dissipative, associated with Joule heating, and is coupled to the field-aligned current (FAC or Birkeland current), although it is often smaller than the non- 


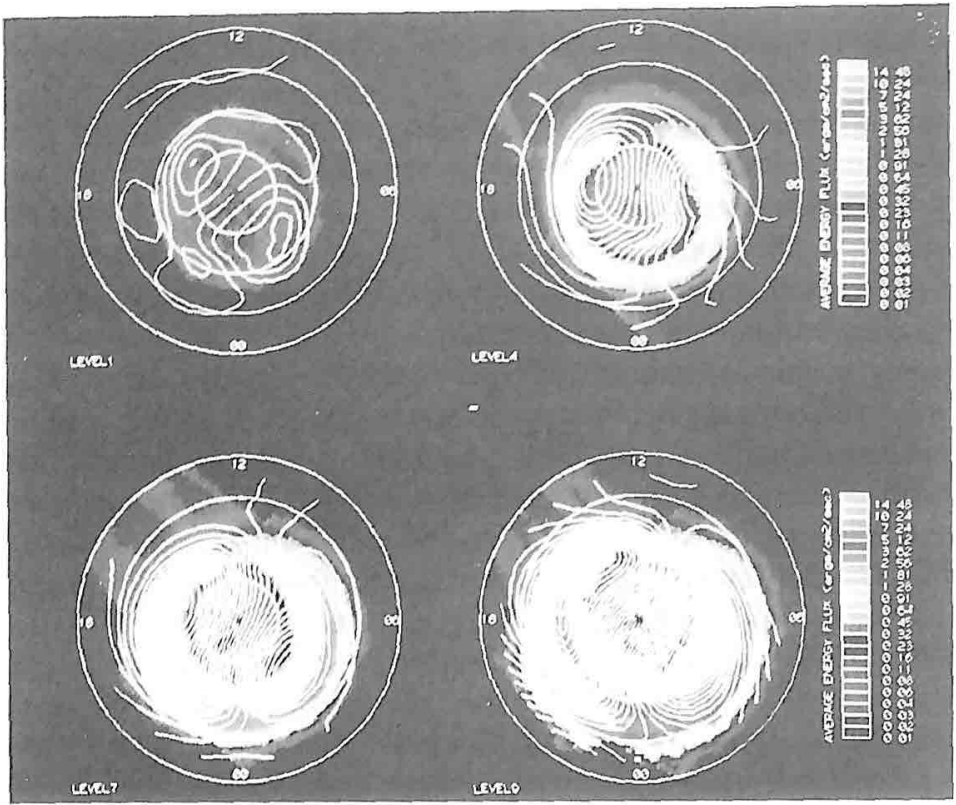

Fig. 1. This figure shows statistical patterns of auroral particle energy influx and equipotential convection contours for four increasing levels of geomagnetic activity.

dissipative Hall component (perpendicular to $\underline{E}$ ). The FAC provide the effective means of coupling energy and momentum from the solar wind, via the magnetopause and magnetosphere to the ionosphere and thermosphere. Both the FAC and the Pedersen currents within the auroral ionosphere intensify sharply as geomagnetic activity increases. For a given electric field, the efficiency of momentum transfer and the Joule heating both increase linearly with ionosphere plasma density. Since the energy deposition associated with Joule heating usually exceeds that from direct particle precipitation by a factor of 3-5 (REES et al., 1986), knowledge of the plasma convection pattern, and of the ionospheric plasma density response to precipitation, is particularly important. The auroral and polar regions which display the imprints of these magnetospheric phenomena also show characteristic signatures in the energetic charged particle populations, the $\mathrm{AC}$ and $\mathrm{DC}$ electric and magnetic fields, and emissions of the optical aurora.

The signature of increasing geomagnetic activity, that is, of intensifying convective electric fields and precipitation, and an equatorward expansion of the regions affected, implies a considerable increase in ionospheric currents: the auroral electrojets. The FAC, Joule heating and ion-drag wind acceleration must therefore also increase, as related parts of the system transferring mass, charge, energy and momentum throughout the magnetosphere, and polar ionosphere and thermosphere regions. The temporal and spatial variability of all of the previously-mentioned term,- "geomagnetic forcing"-also increases, particularly at very high activity levels. Disturbances of the lower ionospheric regions, within the normal $E$ region 105-120 km, respond directly to "auroral" ionisation (REES and FULLER-RowELL, 1989). At higher activity levels, strong interactions between the ionosphere and the induced 
chemical and dynamical changes of the thermosphere cause the ionospheric response to become much more complex, and rather more difficult to model and interpret, particularly at upper thermospheric, $F$-regions, altitudes (REES and FULLER-ROWELL, 1989; SCHUNK, 1989, 1991). Following an initial high-latitude disturbance, propagating waves affect all latitudes. Thermospheric compositional changes are forced by the new circulation patterns, which may force some very large, and long-lasting, disturbances of the ionosphere (FULLER-ROWELL et al., 1991a). During major geomagnetic disturbances, the decay of energetic ions from the ring current particles (TINSLEY et al., 1988), may cause additional low-latitude distances of the thermosphere and ionosphere.

In terms of future observational requirements, therefore, the entire sequence of parameters mentioned above are targets. Precipitation, convection, field-aligned and horizontal electrojet currents can be thought of as the primary mechanisms, while induced changes of plasma density, conductivity, neutral winds, and the consequences of strong heating of ions, electrons and neutrals have extremely important roles in the subsequent development of the entire coupled magnetosphere-ionosphere-thermosphere system.

It is an obvious comment that the easy observations have already been made, and that the difficult objectives remain to be done. Global imaging of precipitation and ionospheric conductivity is already a reality. Global imaging of ionospheric convection and of thermospheric winds is entirely feasible, but new missions require a major commitment by Space Agencies and National Funding Agencies. Mapping of Hall currents is becoming a reality with networks of modern ground-based magnetometers. However, the derivation of dissipative Pedersen Currents and the FAC system requires further data from space instrumentation. Direct measurement and mapping of the two-dimensional polar convection pattern, and of the thermospheric winds which also drive "back-EMF" affecting the total EMF, will certainly aid understanding the magnetospheric circuit, and its response to solar wind forcing from the outside, and the feedback effects of induced changes in the ionosphere and thermosphere from the inside. Mapping of hot magnetospheric plasma distributions, via the interactions of energetic magnetospheric particles with thermal hydrogen of the geocorona, and the "imaging" of the subsequent energetic neutrals by a suitable instrument has already been demonstrated (ROELOF, 1987). This technique will be further exploited in the future to obtain global images of the changing distributions of energetic particles in the ring current, for example during geomagnetic disturbances.

\subsection{Current observational methods}

The current observational techniques which will be reviewed are based on three experimental systems which have been successfully adapted to observing the high-latitude thermosphere during the past decade. These, and other instruments, have also been used to study low and mid-latitude phenomena. The bulk of the data have come from studies involving the Dynamics Explorer Satellites, networks of ground-based Fabry-Perot interferometers, and advanced radars such as the Incoherent-Scatter radars at the European Incoherent Scatter Facility (EISCAT), Millstone Hill and Sondre-Stromfjord, and coherentscatter radars such as that used by MANSON and MEEK (1980) for mesosphere-lower thermosphere studies, and the Scandinavian Twin Auroral Radar Experiment (STARE) and Polar Anglo-Canadian Experiment (PACE) radar used for studying high-latitude plasma convection.

Dynamics Explorer-2 (DE-2) carried two wind-measuring instruments, the Fabry-Perot interferometer (FPI, HAYS et al., 1981) and the Wind and Temperature Sensor (WATS, 
SPENCER et al., 1981). The FPI observed meridional winds, and the WATS the zonal component. These could be combined, as demonstrated by KILLEEN et al. (1983) to give the full wind vector at upper thermospheric altitudes. DE-2 also carried an effective battery of instruments capable of observing a wide range of ionospheric properties (HoFFMAN and SCHMERLING, 1981) and the major elements of the magnetospheric input to the high-latitude ionosphere and thermosphere. DE-1, from a more elliptical orbit, was additionally able to map large-scale auroral images, and further study the detailed physics of magnetospheric processes and interactions out to about 4 earth radii. The important contribution of the DE-2 instrumentation to our understanding the polar thermospheric wind systems can be gleaned from papers such as HAYs et al. (1984), KILLEEN et al. (1983, 1985, 1986, 1988), REES et al. (1983, 1984, 1986), RoBLE et al. (1983, 1984) and REES and FULLER-ROWELL (1989).

Fabry-Perot interferometers were initially adapted to observe auroral emissions, line widths and Doppler shifts by ARMSTRONG (1969). However, systematic application of the High Resolution FPI to study the behaviour of high-latitude thermospheric winds occurred in the late 1970s and early 1980s (HAYS et al., 1979; SMITH and SWEENEY, 1978; REES et al., 1980, 1981, 1982; MERIWETHER, 1983; MERIWETHER et al., 1984; HERNANDEZ, 1986; HERNANDEZ and KILLEEN, 1987). Recently, the Field-Widened MICHELSON (THUILLIER et al., 1990) and the equivalent for the Fabry-Perot Interferometer-the Doppler Imaging System (REES et al., 1983; BATTEN et al., 1988; REES et al., 1989) have shown the promise of providing ground-based snap-shots of the motion of the upper mesosphere, thermosphere and ionosphere over regions of several hundred $\mathrm{km}$ in diameter. Such new measurements provide detail and time-resolution which cannot be matched by the previous generations of instruments which have to sequentially scan the sky region by region. However, from the ground, such instruments can only obtain information on height structure of wind, temperature etc. by selecting between a range of discrete emissions which can be identified with specific (and preferably narrow) height intervals.

One of the most valuable physical quantities which can be directly obtained from incoherent scatter radar (ISR) Doppler shift data is ion drift velocity. Given ion drift vectors and plasma density as a function of altitude, the neutral wind speed may be deduced. In the $F$ region, the ion drift component along the local magnetic field is due to a combination of a parallel electric field component, gravity, the component of the meridional neutral wind resolved along the magnetic field and ambibipolar diffusion (BANKS and KOCKARTS, 1973; RISHBETH, 1972). This method has been demonstrated to produce reliable meridional neutral wind values, in accurate agreement with ground-based optical interferometric observations (REES et al., 1984; WICKWAR et al., 1987; MERIWETHER et al., 1985; WINSER et al., 1988), with the obvious advantage that radar observations can be continued through cloudy periods and during sunlit periods (including polar summer). Derivation of the high latitude thermospheric zonal neutral wind component from ISR data alone has yet, however, eluded a generally satisfactory analysis (REES et al., 1984; ALCAYDE and FONTANARI, 1986; ALCAYDE et al., 1986; WINSER et al., 1988).

Even with the experimental technique advances described earlier, the available data base is fragmentary, combined of individual instruments at individual stations and individual satellite orbits: many of the most interesting results have been the result of serendipity. Coordinated observing campaigns have recently involved large numbers of ground-based stations distributed at high and mid-latitudes in both hemispheres. These projects started in the era of the DE-2 and VIKING satellites (1981-1985), and have continued as coordinated optical and radar observing programmes such as GISMOS, GITCAD, WITS and WAGS etc. 
which provide data on a truly global basis. The Lower Thermosphere Coupling Study (LTCS), and several new initiatives under the auspices of the Solar Terrestrial Energy Program (STEP) will make further contributions. The number and capability of individual stations has increased under the recent sponsorship of programmes such as the NSF CEDAR initiative (Coupling of Energy and Dynamics through the atmospheric Regions).

\subsection{Novel experimental system; imaging structure and dynamics}

The Fabry-Perot interferometer on NASA's Dynamics Explorer-2 spacecraft, a very small and modest instrument, provided a glimpse of the capability of a space-borne limbscanning optical instrument for elucidating the structure, temperature and dynamics of the thermosphere. Further and more advanced instruments of this type, the High Resolution Doppler Imager (HRDI) and WIND Imaging Interferometer (WINDII, a field-widened Michelson Interferometer) instruments on NASA's Upper Atmosphere Research Satellite (UARS) are expected to provide a further leap forward, particularly in the study of upper atmospheric dynamics and energetics. They will also make a major contribution via providing, along with the other thermal infrared and microwave instruments on UARS, the broad combination of measurements of atmospheric properties needed for the next generation of studies of the complex interactions between atmospheric chemistry, radiation and dynamics in the stratosphere, mesosphere and thermosphere, and of the complex inter-level interactions which ocurr.

However, a full interpretation of many of the phenomena which occur in the ionosphere and upper atmosphere, from mesospheric levels to the upper thermosphere, requires series of large-scale images of the structure and dynamics. As illustrations, a few examples of recent studies combining ground-based and space-borne measurements will be used.

Figure 2 shows one of the auroral images obtained in the near-UV by the HILAT satellite (Ref: John Hopkins Report, 1984). The wealth of detail in the auroral luminosity structures can be contrasted with the very broad features shown in the statistical models of electron precipitation (i.e. Fig. 1). The Spin-Scan Imager on NASA's Dynamics Explorer-1

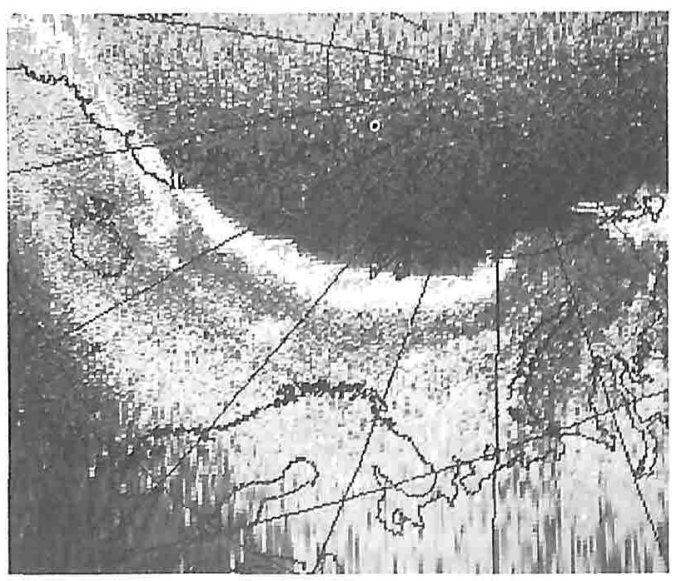

Fig. 2. This figure is one of the auroral images obtained in the near-UV by the HILAT satellite (John Hopkins Report, 1984). 

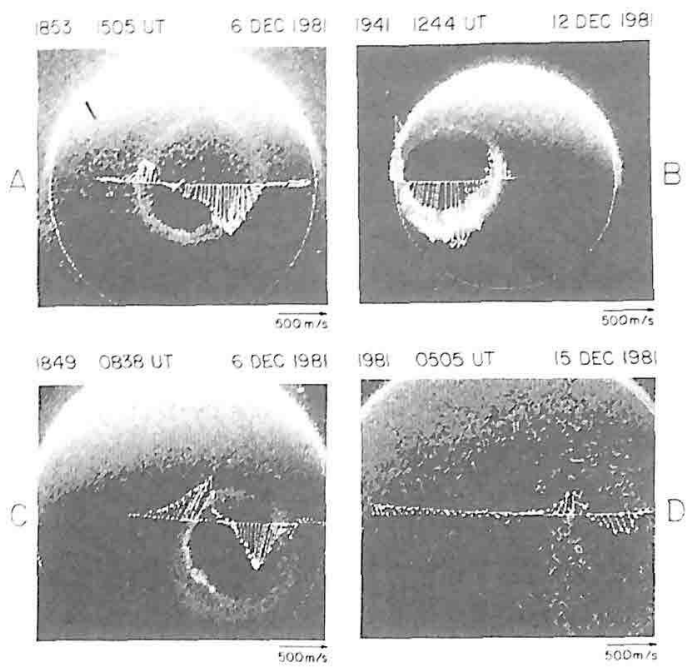

Fig. 3. The DE-2 and DE-1 spacecraft simultaneously observed the northern auroral oval on a number of occasions during the winter of 1981/1982 (KilleEN et al., 1988). These four elements were obtained on Dec. 6, 1981, at 15:05 UT; Dec. 12, 1981, at 12:44 UT; Dec. 5, 1981 at UT: and Dec. 15, at 08:38 UT, and Dec. 15, at 05:05 UT, respectively. DE-2 provided the wind vectors, while the largescale auroral images were obtained from the DE-1 Spin-scan imager.

Spacecraft (FrANK et al., 1981) has obtained many series of images describing the spatial and temporal evolution of electron precipitation over the auroral ovals and polar cap during geomagnetically-disturbed periods.

The Dynamics Explorer satellites observed a wide range of geomagnetic activity conditions and individual events. Figure 3, taken from KILLEEN et al. (1988), was obtained by combining with data from the WATS and FPI instruments onboard DE-2, with that of the Spin-Scan Imager (FRANK et al., 1981) onboard DE-1. For each of the four intervals depicted, DE-1 was near apogee over the northern polar region while DE-2 was passing underneath, close to its perigee (near $300 \mathrm{~km}$ ). The results, in each case, show the classical neutral wind signatures of the auroral oval and polar cap: strong sunward winds associated with the optical emissions dusk auroral oval, weaker sunward winds in the vicinity of the dawn auroral oval (sometimes only a slight reduction of the antisunward flow, REES et al., 1986). The "dark" polar cap contains a region of strong antisunward flow (flows from $400-1000 \mathrm{~ms}^{-1}$, depending on activity, contrasting with a mere $100-200 \mathrm{~ms}^{-1}$ due to purely solar forcing). At latitudes lower than those of the auroral oval, there is a general antisunward flow of around $150-200 \mathrm{~ms}^{-1}$.

The four events cover a very wide range of activity and detailed response. The extremes of activity are depicted by elements B (Dec. 12, 1981) and D (Dec. 15, 1981). Element B shows the situation at 12:44 UT, soon after the start of the very disturbed period, when the auroral oval was greatly expanded and very active. The peak winds within the dusk auroral oval and polar cap reached nearly $1 \mathrm{kms}^{-1}$ during this event. Element D, in contrast, shows a very quiet period, with weak, only just discernible, optical emissions and an auroral oval contracted poleward. Although the auroral emissions were very weak, the wind signature was still distinct, but the peak sunward wind speeds were less than $200 \mathrm{~ms}^{-1}$. 
Element A (Dec. 6, 15:05 UT) shows a more complex situation: there was a strong $\left(600-800 \mathrm{~ms}^{-1}\right)$ antisunward flow in the polar cap, confined to the dawn side of the polar cap. On the dusk side, the antisunward flow was generally weak, and there was a limited region of sunward flow. This period was one with a northward IMF component, however, with relatively strong total magnetic field strength. Sunward winds in the dusk auroral oval were relatively weak, less than $300 \mathrm{~ms}^{-1}$.

Element C shows data from Dec. 6, 1981, 08:38 UT (southward IMF). On this occasion, the sunward winds within the dusk auroral oval matched the winds within the strong antisunward jet on the dawn side of the polar cap. The Y component of the IMF was positive, driving (HEPPNER and MAYNARD, 1987) a strong convection vortex connecting the dusk oval and dawn polar cap, and leaving weak convection (and very weak sunward winds, for a relatively disturbed period), in the dawn auroral oval. This can be contrasted with Element B, which shows symmetric antisunward flow within the polar cap, and $300 \mathrm{~ms}^{-1}$ sunward winds in the dawn auroral oval (30\% of the peak dusk oval sunward winds). The Y component of the IMF was rather small during most of the Dec. 12, 1981 event (Element B).

A detailed analysis of the situation displayed in Element $\mathrm{A}$ is shown in Fig. 4 (also taken from KILLEEN et al., 1988). Included in these presentations are the additional data

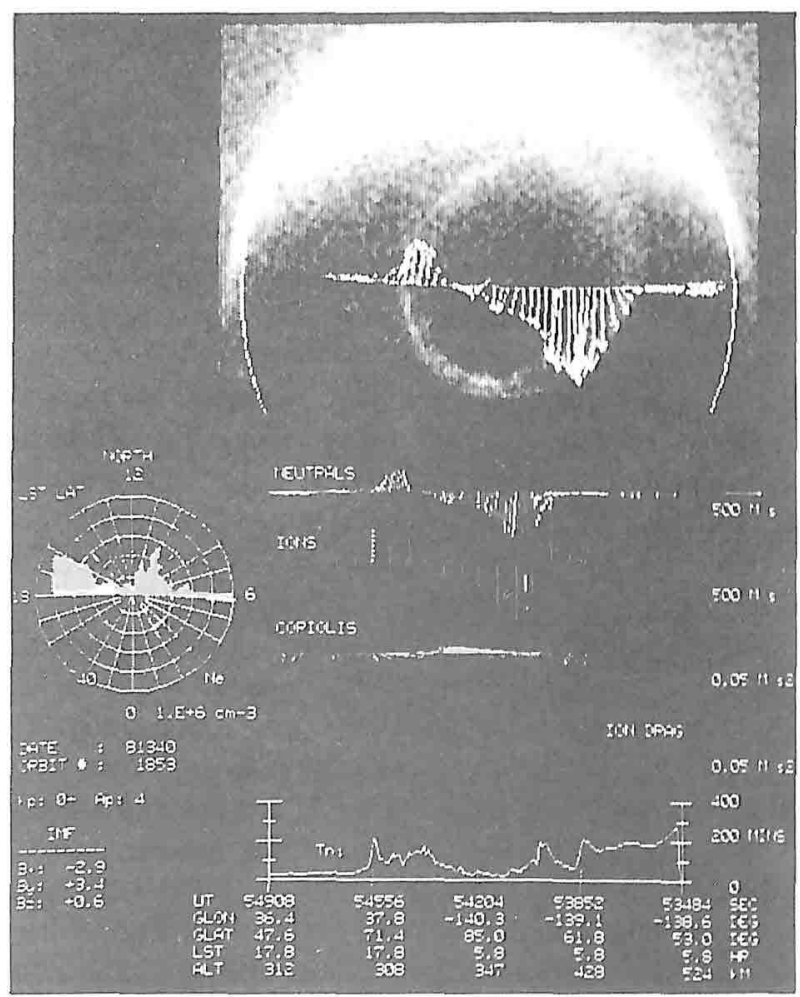

Fig. 4. This figure displays a detailed study of the situation shown in element A of Fig. 5 (KILLEEN et al., 1988). Properties of the thermal plasma (ion density and ion drift) within the polar region are shown, along with a determination of the ion-neutral collisional time constant, and an analysis of the most important forces coupling the high-latitude ionosphere and thermosphere. 
available from the Ion Drift Meter (IDM, HEELIS et al., 1981) and the Langmuir Probe Instrument (LAPI, KREHBIEL et al., 1981). The former provided the electric field component equivalent to the ion velocity perpendicular to the satellite track (zonal component), while the LAPI provided thermal plasma density, shown in the section at left. The thermal plasma density has been used to calculate the ion-neutral friction coupling time constant, shown in the lowest panel of Fig. 4.

Impressive and highly valuable as these image sequences and studies are, they still only represent "snapshots" of the magnetospheric inputs, and of the subsequent response of the polar ionosphere and thermosphere. In particular, the thermospheric and ionospheric "response" has only been observed from ground-based measurements and when suitablyequipped satellites slice through the auroral oval. Serendipity, as much as planning, has provided most of the occasions when spacecraft in both high and low earth orbit happen to be in suitable locations to provide comprehensive observations during the active phase of an interesting event. The true global response of the polar ionosphere and thermosphere has never been "imaged", let alone studied in the sense of a "time-sequence".

Earlier, we reviewed the requirements for series of measurements of highly critical parameters as global distributions or image, in addition to those of electron precipitation:

Ionospheric Plasma; Upper Mesospheric and Thermospheric Constituents; Polar convective Electric Fields; the Storm Ring Current Population; the Neutral Wind system; the Joule Heating Distribution; the Ionospheric Current System, and the Field-aligned Current System (FAC).

The first and second requirements are both complex, since there are many quasiindependent ionospheric and neutral constituents whose distributions need to be studied individually. The Remote Atmospheric and Ionospheric Detection system (RAIDS) investigation (MCCOY et al., 1986) to be flown on a forthcoming NOAA/TIROS spacecraft, and instruments to be flown on the NASA Upper Atmosphere Research Satellite (NASA UARS report 3/1989), will use a variety of instruments, mainly limb-scanning, to observe a number of optical emissions due to key constituents in the thermal infrared, the near infrared, the visible and the ultraviolet parts of the electromagnetic spectrum. The infra-red and microwave techniques have been deployed on many previous space missions, and their capability of mapping constituent distributions in the stratosphere and mesosphere is well demonstrated. The abilities of the new optical techniques and instruments, utilising the visible, near IR and UV/EUV spectrum have not been so well exploited thus far, but have a very considerable promise for extending the mapping to new regions and constituents. Additionally, the availability of direct measurements of wind in the stratosphere, mesosphere and thermosphere, as opposed to winds inferred from application of geostrophy to temperature field data, will be exceedingly valuable. The combination of tried and trusted techniques, with the additional exploitation of new techniques and instruments providing global measurements, will greatly improve our ability to monitor the distributions and variations of these constituents, and to understand the interactions between atmospheric chemistry, radiation and dynamics.

Much of our current understanding of polar convection, and of thermospheric neutral winds has come from in-situ diagnostics (electric field, neutral winds) or from limb-scanning Fabry-Perot interferometer on Dynamics Explorer (neutral winds), producing single-orbit sequences of data. Significant recent advances into imaging the instantaneous polar convection pattern have come from recent studies using the STARE Radar in northern 
Scandinavia, and the PACE radars combining two similar radars in Antarctica and Goose Bay, Canada.

Plate 1 summarises a study which combined spectacular results from the STARE Radar with large-scale auroral imaging from the VIKING satellite [Eos]. The upper left panel shows a simple model of polar ion convection, placing the region observed by STARE and VIKING into its overall context. The lower left panel shows the large-scale auroral image obtained from VIKING, highlighting the region observed by the STARE radar. The image on the right shows the convection pattern vectors derived from the STARE radar, superimposed on the auroral luminosity image obtained at the same time and location from the VIKING UV imager. The STARE ion flows show the general sunward rotation of ion flows crossing from the polar cap into the dawn sector of the auroral oval, but also demonstrate that there are important flow structures within auroral oval regions which look quite homogenous in the VIKING image. The STARE results confirm that the mean convection models do not reflect important details of temporal and spatial structures of the polar ion convection pattern. It is also impossible to derive the structures of the plasma convection pattern from the images alone (highly valuable as they are for many other purposes).

The techniques reviewed and described by ROELOF (1987) will be utilised to image the ring current distribution. During disturbed periods, much of the total energy input from the solar wind acts to enhance the ring current population, as noted by the increasing $D_{\mathrm{st}}$. The subsequent decay of the "temporary" ring current population, via the magnetotail, and via precipitation into the low-mid-latitude thermosphere/ionosphere, has been rather poorly observed and is not understood in detail.

The traditional ground-based Fabry-Perot interferometer scans sequentially the sky to obtain vector wind data. The Doppler Imaging System (DIS, REES and GREENAWAY, 1983; REES et al., 1983, 1986, 1989; BATTEN et al., 1988) is a field-widened FPI using a 2dimensional Imaging Photon Detector. This ground-based instrument can map wind vectors over a region up to around $800 \mathrm{~km}$ diameter (at thermospheric altitudes of $240 \mathrm{~km}$ ). Figure 5 shows a sequence of thermospheric wind maps (REES et al., 1989) obtained from Kiruna, Nothern Sweden, in the same region, and during a similar disturbance to that observed (Plate 1) with the STARE radar and the VIKING UV imager.

The region displayed in this instance is approximately $470 \mathrm{~km}$ diameter, centred on Kiruna, and the wind vectors at approximately $240 \mathrm{~km}$ (OI $630 \mathrm{~nm}$ ) are displayed The vector wind maps were obtained at approximately 10 minute intervals during a geomagnetically disturbed period, between 22:30 and 23:30 UT, after local magnetic midnight. During this disturbance, the "mean" wind vector rotated from southwestward to southward during the 1 hour period. During this period, and the subsequent hour, the magnitude of the wind underwent several surges in magnitude and rotational changes of the order of $100 \mathrm{~ms}^{-1}$ and $+/-30^{\circ}$, respectively, while the auroral luminosity (OI-630 $\mathrm{mm}$ emission: background scalar) also varied strongly. By 00:30 UT (not shown), the mean wind vectors were southeastward, with mean wind speeds of the order of $300-400 \mathrm{~ms}^{-1}$.

The anti-clockwise rotation of the wind vector was produced by ion drag in the region of sunward ion flows of the auroral oval, as depicted in Plate 1. Although this was on a different occasion, the ground-based magnetic records and the overall auroral morphology (scalars of background intensity in Fig. 5), indicated that throughout this period, Kiruna and the region observed by the DIS, were within a region of strong sunward ion flow in the dawn auroral oval. It has been unfortunate that in the past several years, it has not proved possible to find periods of suitable weather and auroral/ionospheric conditions so that the STARE radar and 


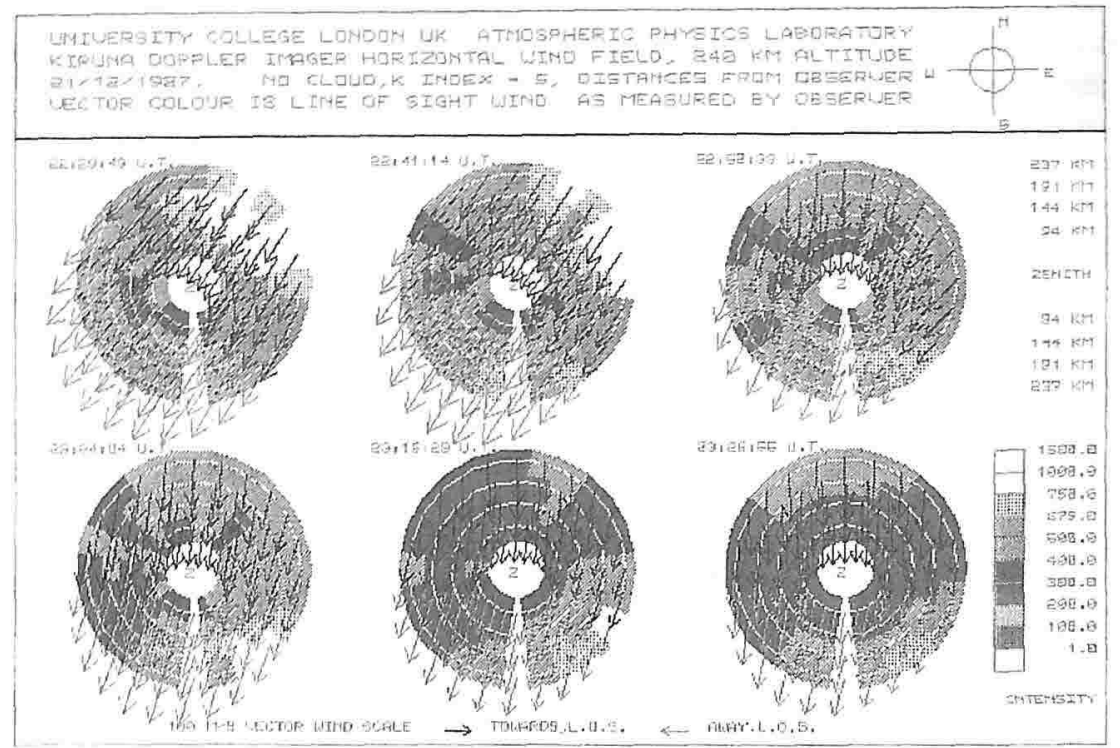

Fig. 5. This figure shows a sequence of thermospheric wind maps (REEs et al., 1989) obtained from Kiruna, Northern Sweden, in the same region, and during a similar disturbance to that observed (Plate 1) with the STARE radar and the VIKING UV imager.

DIS observations could be properly combined, possibly during over-passes of one of the VIKING, DE-1, HILAT, POLAR BEAR or DMSP spacecraft carrying auroral imagers. Combining and correlating such data sets has to be a major target for the forthcoming STEP period.

In Fig. 6, data from the PACE and Goose Bay radars are shown from the period April $20-22,1988$, when a pre-planned program of conjugate point observations with these two powerful radars was carried out (BAKER et al., 1989). This study demonstrated that it was possible to map simultaneously the convection patterns in both the northern and southern auroral oval/polar cap regions. Moreover, by covering a large-enough region, it was possible to demonstrate that during a period when the IMF $B_{Y}$ component was strongly positive for a period of some hours, the convection patterns presented by HEPPNER and MAYNARD (1987) for such conditions (complementary patterns: $\mathrm{BC}$ pattern in the north, and the DE pattern in the south) actually provided a reasonable explanation of the observed line-of-sight Doppler shifts. This was a very important result and demonstrated very clearly the advantage of obtaining conjugate measurements of large-scale maps of feature and flows.

\subsection{Numerical models and methods of deriving conductivities, heating and currents}

The most fundamental influence of the magnetosphere on the polar/auroral thermosphere is the direct consequence of magnetospheric plasma convection. This convection drives rapid motion of plasma throughout the ionosphere of the polar cap and auroral oval. The structure and variability of polar convective fields were not well understood until the 1960's and 1970's, with the advent of rocket and satellite measurements of ion drifts and electric fields 


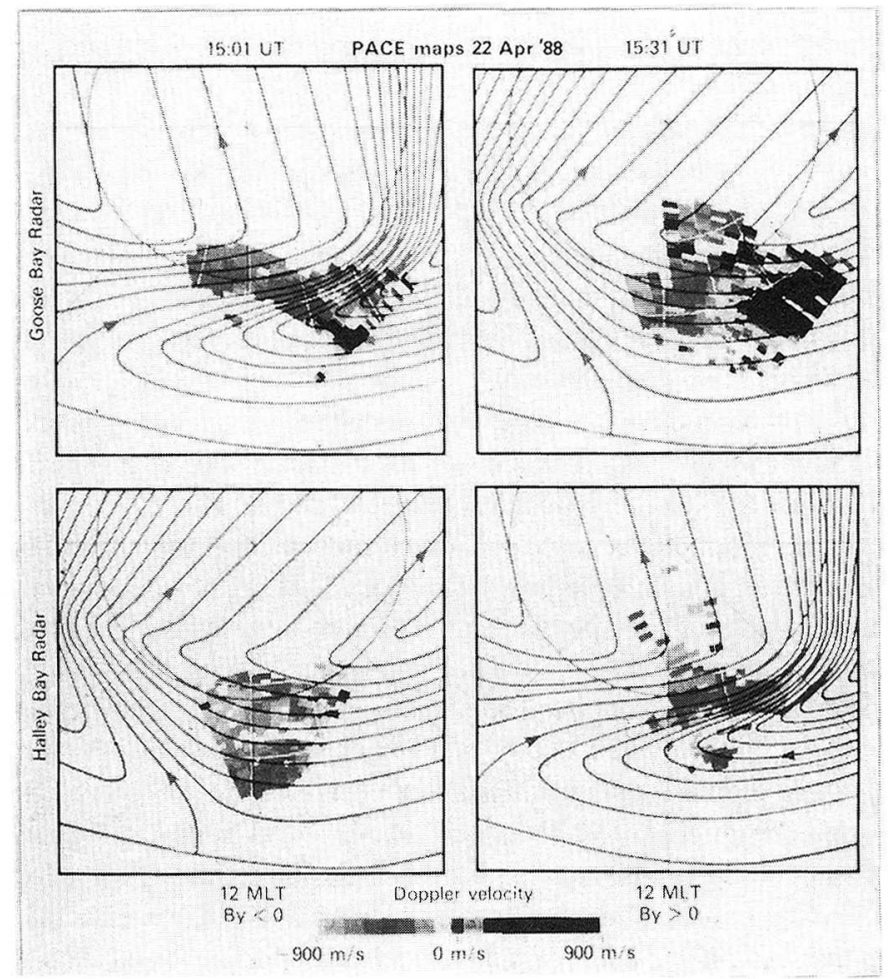

Fig. 6. This figure shows conjugate ion drift data obtained from the PACE and Goose Bay radars on April 20-22, 1988 (BAKER et al., 1989).

(HEPPNER 1977; HEPPNER and MAYNARD, 1987). The effect of the plasma convection on the thermosphere depends (among many other factors) on the plasma density. Plasma density is controlled by the combination of photoionization and energetic particle ionisation, a variety of recombination processes and transport, both by convection, and by the neutral wind. Rapid plasma motions, combined with moderate or high plasma densities, can rapidly accelerate high speed winds in the auroral thermosphere via the process commonly known as ion drag (RISHBETH, 1972).

The resulting ion-neutral frictional drag causes direct heating of both ions and neutrals, commonly known as Joule heating (COLE, 1962, 1971). Resulting changes in temperature affect pressure gradients which also modify the winds. Such induced winds (or more correctly, changed winds, since there is always a complex wind system in existence prior to a given geomagnetic disturbance) may increase or decrease (but generally decrease) the ion drag, the resulting frictional heating, and the local electrojet current by changing the electromotive force $\left(\underline{E}+\underline{V}_{n} \wedge \underline{B}\right)$. The induced winds may also induce a "back-EMF", opposing the initial magnetospheric convective electric field. This modified wind system will also induce or change ion drifts parallel to the local magnetic field. Such "parallel" ion drifts will affect field-aligned electron flow, required to maintain quasi-charge neutrality. Thus the entire vertical plasma distribution will respond to wind changes, an effect which becomes increasingly important at greater $(F$-region) altitudes. Changes of the ion density distribution 
will modify the subsequent ion drag on the neutrals, and thus the wind acceleration terms, and finally the winds themselves.

The FAC power the magnetosphere-thermosphere forcing process. The spatial distribution of FAC may be determined from single orbit passes by a suitable satellite magnetometer (HOFFMAN et al., 1985). In the vicinity of the auroral oval and polar cap, there are always various contra-flowing streams of field-aligned thermal and supra-thermal charged particles and it is often difficult to identify the net carriers of the FAC by direct observation. Variations of the FAC caused by ionospheric feedback processes are important, first-order, changes but are difficult to observe directly.

It is not yet possible to observe the global distributions of both plasma convection and energetic particle precipitation as a function of time. The response of the entire ionospherethermosphere system, the distributions of neutral temperature, density, and winds, the ionospheric response, ionospheric conductivities and current and the related FAC, can be investigated by using numerical modelling techniques. These provide an overall picture of the way in which these important parameters inter-relate, but one which is necessarily limited by the available maps of convection and precipitation which are used as basic input data. REES and FULLER-ROWELL (1989) have described how the UCL-Sheffield coupled ionospherethermosphere model (FULLER-ROWELL et al., 1987) can be used to derive these quantities from abinitio calculations and empirical models of precipitation and convection.

Figure 7 shows the distribution of ion convection and height-integrated Joule Heating over the northern polar region, computed by the UCL-Sheffield Model for NOAA/TIROS Activity Level 7. The values shown allow for all the feedback effects and interactions contained within the UCL-Sheffield coupled model. The double-horseshoe structure in Joule Heating may appear somewhat surprising. It is partly the effect of $E$-region neutral winds induced by ion drag, increasing the total EMF in some regions, and decreasing it in others

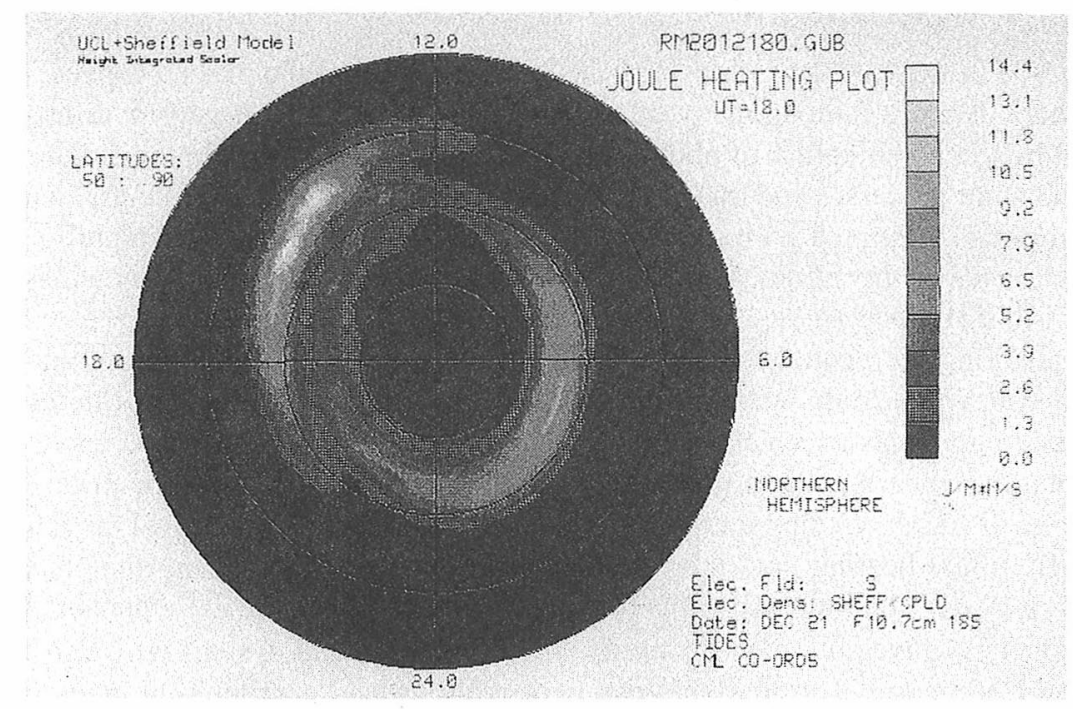

Fig. 7. This figure shows the distribution of ion convection and height-integrated Joule Heating computed by the UCL-Sheffield coupled ionosphere-thermosphere Model, in the northern polar regions for NOAA/TIROS Activity Level 7. 
(REES and FULLER-ROWELL, 1989). The Joule heating distribution, even for the same patterns of polar convection field and electron precipitation, show considerable variations with Universal Time, and with season (REES et al., 1989). These variations result from the changing combination of solar and particle ionisation sources (subtly modified by changing winds, neutral and ion composition etc.). The combination of seasonal and UT modulation of Joule heating, resulting from changing solar photo-ionisation, can be very large, a factor of about 4-5, even though the same patterns of convection and precipitation are forcing the entire systems. We really understand very little about the nature of the magnetospheric source-the conditions under which it may act as a constant voltage or constant current source.

Distributions of the horizontal current density combined with the associated FAC (corresponding to Fig. 7) are shown in Fig. 8. The FAC were derived within the numerical model by computing the divergence of the horizontal current system. The FAC distribution indicates the demand on the magnetosphere to satisfy the requirement for current continuity. Upward current is denoted as positive (yellow), downward current is negative (blue). The region 1 and region 2 FAC can be clearly seen in both the dusk and dawn sectors of the auroral oval.

Using these thermosphere-ionosphere models, given a magnetospheric convection electric field, the horizontal, ionospheric current distribution, the FAC system and momentum transfer between the magnetosphere and the thermosphere can be calculated selfconsistently. This is highly instructive, it demonstrates, for example, that if the magnetosphere is a voltage source, there are very large seasonal and hemispheric asymmetries in FAC etc. resulting from asymmetric solar illumination and photoionisation within the auroral and polar ionospheric $E$-regions. This will lead to the strong UT and seasonal modulation of the auroral electrojets and Joule region Heating described above and in REES and FULLER-ROWELL (1989). There is rather little supporting experimental evidence, a possible indication that the dayside FAC are indeed stronger in summer than in winter (as is

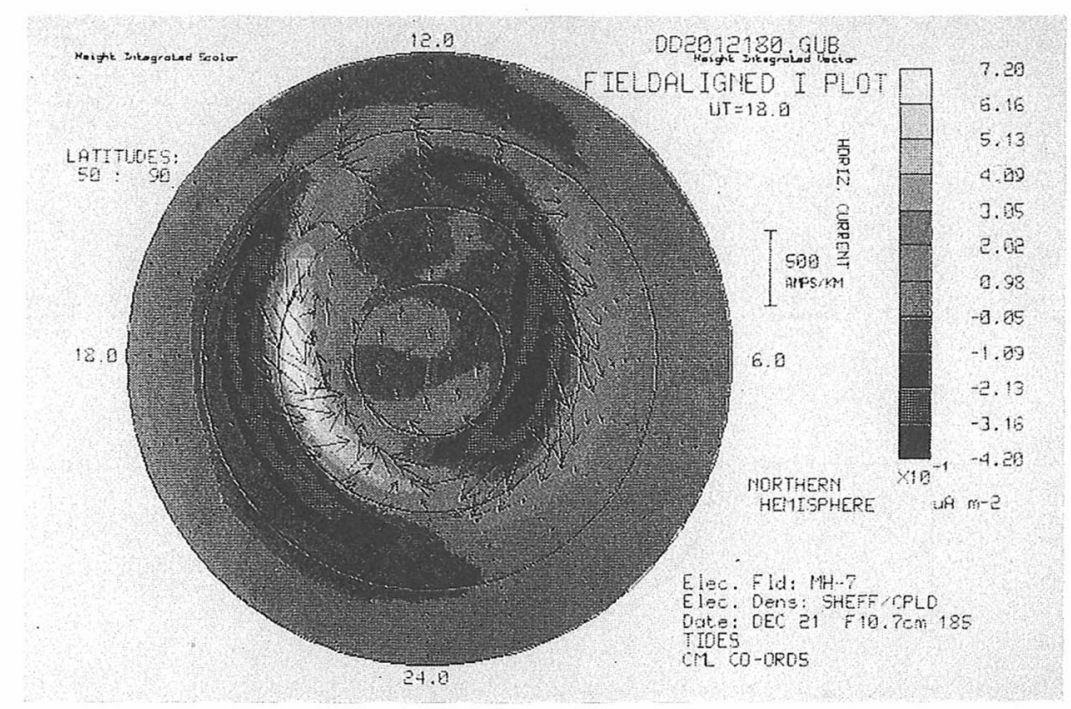

Fig. 8. This figure shows the computed horizontal current density distribution and the associated Field Aligned Current (FAC) distribution corresponding to Fig. 7. 
predicted by the above model). However, it would be a glib simplification to assume that the magnetosphere is always a voltage source. We should suspect that, for some regions and phenomena, a lack of available charge carriers (of whatever sign or energy range) must cause the magnetosphere to be "current limited".

Naturally, in regions and at times where the magnetosphere becomes current limited, some of the assumptions used in the UCL-Sheffield model (and in the rather similar efforts

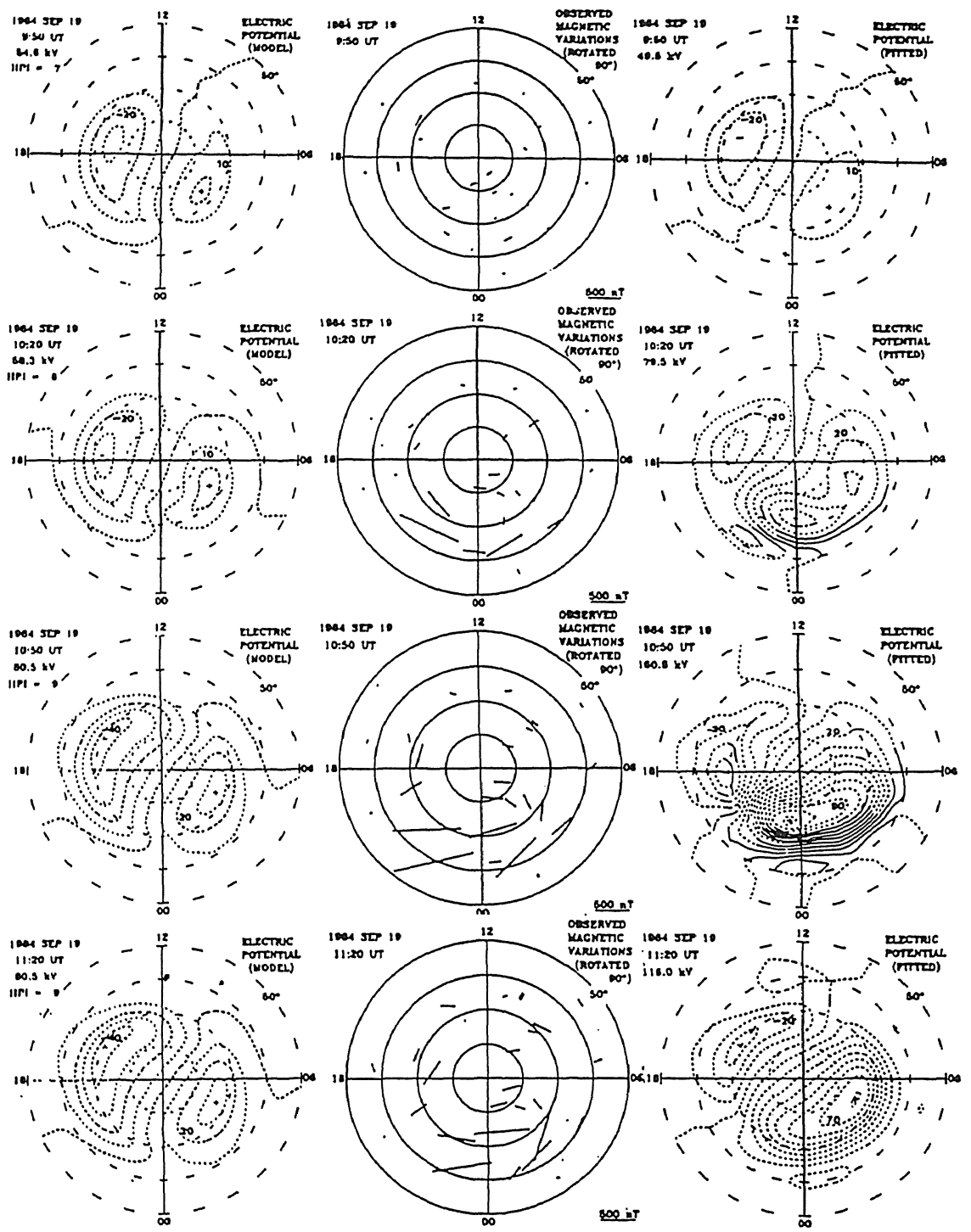

Fig. 9. This figure shows statistical electric potential patterns and fitted electric potential patterns for selected times for a substorm on Sept. 19, 1984, using the technique of Assimilative Modelling of Ionospheric Electrodynamics (Plate 1, KNIPP et al., 1989). 
using the NCAR Thermosphere-Ionosphere General Circulation Model (TIGCM)) become unreliable. To resolve some of these questions, preliminary experiments coupling the UCL/Sheffield Model with the Rice Convection model have been discussed by FULLERRowell (1990). The Rice Convection Model includes the "magnetospheric physics" identifying charge carriers, and self-consistent limits to the FAC and EMF of the magnetospheric circuit. As yet, it has only been possible to interchange data sets between these models, and no clear answers have emerged. Coupling these large numerical models is no simple matter, and the results of further studies are awaited with considerable interest.

An alternative approach has been discussed by RICHMOND and KAMIDE (1988) and KNIPP et al. (1989). They commence with empirical baseline models of conductance and of magnetospheric electric potential, and proceed by using a technique they have developed to assimilate available empirical data on ionospheric currents deduced from ground-based magnetometer observations, and measurements of plasma convection, for a specific period of interest. In their technique-Assimilative Modelling of Ionospheric Electrodynamics (AMIE), the parameters of the model are recomputed to best fit the available data, generating models of ionospheric current, potential distribution etc., as shown in Fig. 9. In all cases, however, there is a fundamental limitation due to a shortage of available data from the combination of ground-based networks and space-borne sensors.

The "instantaneous" distributions of currents and potentials shown in Figs. 7 through 9 look "realistic". However, the distributions are limited by the models of the major input parameters. Further, in the present numerical models, if magnetospheric processes which are not considered, invalidate implicit assumptions, neither of these approaches will provide the correct result. The present models can determine a "climatic distribution" of ionospheric current, Joule Heating, FAC and momentum interchange, since they resort to using or adapting relatively simplistic empirical models. New observational large-scale maps of convection, precipitation and winds would provide many additional constraints, testing and validating the many present assumptions. Future validated models will be able to calculate the distributions of many of these interesting quantities with confidence.

\section{Future Techniques for Observing the Global Atmosphere and Ionosphere}

\subsection{Novel ground-based optical instrumentation}

During the past two decades, there have been major advances in the technology of optical components and detectors, particularly of imaging detectors. Additionally, the increasing ratio of power and performance relative to cost of computers and electronic systems, have made possible major improvements of performance of ground-based and spacebased optical instruments, contributing to the new results described earlier. For the FPI, in particular (REES et al., 1989) it has been possible to fully exploit several new technologies. A number of very interesting and important optical and aeronomical emissions in the nearinfrared have become accessible to observation as a result of the recent development of Imaging Photon Detectors incorporating Gallium Arsenide photocathodes. REES et al. (1989, 1990) have shown the advantage which can be obtained when using this detector to observe the Meinel band emissions of Hydroxyl $(\mathrm{OH})$ at $846 \mathrm{~nm}$, providing Doppler winds near 86 $\mathrm{km}$ altitude.

The data quality obtained when observing the IR emissions of $\mathrm{OH}$ can also be achieved with other important near-IR emissions. For example, the Doppler shift of OII at $732 \mathrm{~nm}$ gives a direct measure of ionospheric drift and electric field, while winds can also be 
determined by observing the emissions of OI at $846 \mathrm{~nm}$ and $\mathrm{O}_{2}$ in the Atmospheric Band $(0$, 1) near $860 \mathrm{~nm}$. Such new measurements provide the possibility of new routine ground-based measurements of winds at altitudes which have not yet been amenable to ground-based optical observation. Studies of the atmosphere implicitly require multi-level measurements, and these have been severely curtailed by the limited number of optical emissions amenable to ground-based observation, and the limited altitude range of such emissions.

Figure 10 shows (REES, 1990, unpublished data) a recent experiment, using the FPI at Bear Lake Utah (using a GaAs IPD), and a new wide-angle front-end adaptor, converting the instrument into a Doppler Imaging System. The target spectral source was the $\mathrm{OH}$ emission at $843 \mathrm{~nm}$, and the experiment (using a total full-angle field of view of $100^{\circ}$ ) demonstrated that the DIS concept can be applied to the mesospheric $\mathrm{OH}$ emission. This opens up the future possibility of mapping mesospheric (around $85 \mathrm{~km}$ altitude) winds over horizontal regions of the order of $20-300 \mathrm{~km}$ diameter. Such Ground-Based observations have an enormous future potential for studies of the structure of waves and tides propagating through the mesosphere and into the lower thermosphere.

The DIS can also be used to study the emission of ionised oxygen at $732 \mathrm{~nm}$ directly mapping line-of-sight ion convection velocities from a single station. 2-dimensional ion velocity maps can then be obtained from single station data, as for the OI $630 \mathrm{~nm}$ wind data (REES et al., 1989), by assuming flow continuity and applying a maximum entropy method. Full 2-D ion vector maps can also be derived directly from simultaneous observations from two DIS stations located with overlapping fields of view. The data analysis is then similar to obtaining vector drifts from bistatic observations of 1-o-s Doppler Shifts by the EISCAT or STARE radars. There are two advantages of the optical Doppler shift observations: the Doppler shifts directly correspond to plasma flow, while the echoes used by the STARE radar depend on "irregularities", generated by the plasma flow. Secondly, observations may be obtained from the DIS with higher spatial and temporal resolution than those normally

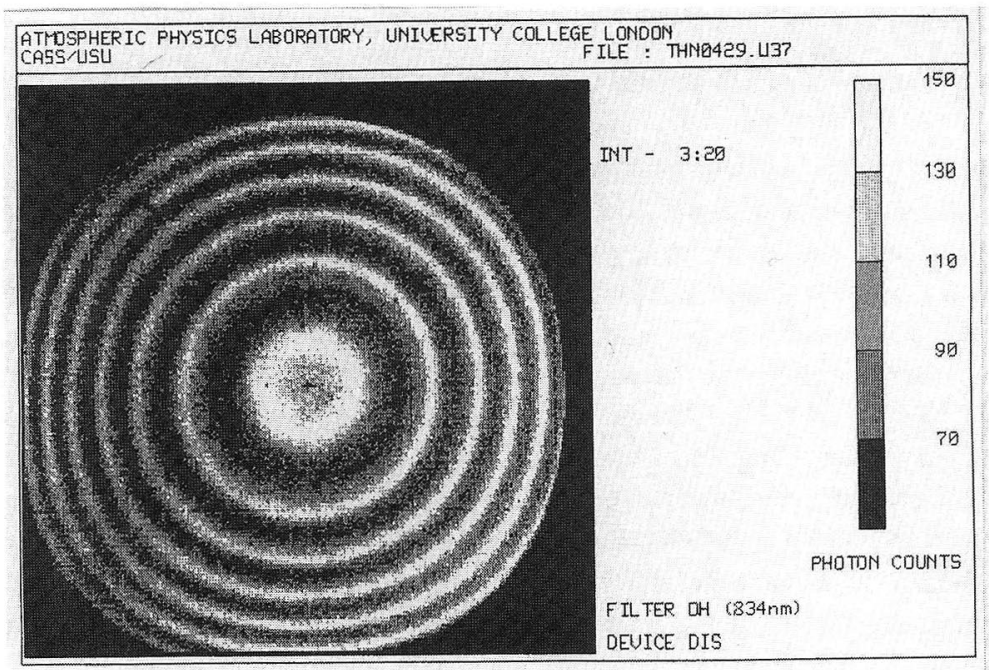

Fig. 10. This figure shows an image of the sky in the $\mathrm{OH}$ line at $843 \mathrm{~nm}$, obtained by the Doppler Imaging System at Bear Lake, Utah (REES 1990, unpublished data). 
obtainable by STARE. There is neither a high velocity limit (the ion acoustic velocity) or, perhaps equally important, a low velocity limit, since the purely optical signal is present whenever either sunlight or precipitation illuminates the ionosphere.

In addition to the high-performance Fabry-Perot interferometers and the field-widened version - the Doppler Imaging System, the field-widened Michelson Interferometer has also been developed and used from the ground to study thermospheric and mesospheric winds and temperatures. MICADO (THUILLIER et al., 1990) and WINDII (SHEPHERD et al., 1984) are two versions of this instrument which exploit the very large etendue possible with the instrument to obtain a combination of wide-field imaging and high time resolution when observing weak aeronomic or auroral emissions. Thus far, despite the enormous potential of such instruments, they have not been widely deployed. They are still rather more expensive and complex to deploy as fully automated systems, while the FPI's have been operated automatically at a number of remote locations throughout the past decade. MICADO is currently deployed in Scandinavia (THUILLIER, 1990, private communication), and it will be interesting to await the measurements from this instrument, when used in conjunction with other optical and radar instruments in the northern Scandinavian region.

There is a great deal of potential for exploiting all of the concepts used in these new ground-based instruments in new instruments to be deployed on future space platforms. However, these possibilities will be surveyed later.

\subsection{Ground-based radars and networks}

Intercomparison of thermospheric meridional winds deduced from Incoherent Scatter Radar (ISR) with those obtained directly from ground-based optical wind measurements have shown that the radar-derived meridional winds around $240-320 \mathrm{~km}$ altitude are normally nearly identical to those obtained by optical interferometric methods (WICKWAR et al., 1984). This is particularly so when the effects of non-Maxwellian ion velocity distribution (REES et al., 1984), and the effect of the neutral vertical wind on the ion velocity component parallel to the magnetic field are allowed for (WINSER et al., 1988).

In principle, it is possible to deduce the zonal wind component from ISR measurements via the ion energy equation. However, this is much more difficult than the meridional wind derivation, since in practice there are a number of ill-defined contributing terms. These include the lack of independent knowledge of the neutral temperature, which is a baseline for the derivation, errors on the individual ion flow components, correction for the usually unknown vertical neutral wind and uncertainty in the $\mathrm{O}_{-} \mathrm{O}^{+}$collision frequency. Further joint experiments, intercomparing optical and radar measurements in a "common volume", are planned and may lead to the understanding required to resolve those situations where a direct ISR analysis would, or would not, allow the reliable deduction of the zonal wind component.

One of the most encouraging developments of the past 5 years has been the commissioning and continued funding of widely spread networks of radars and optical facilities, particularly those new facilities which combine optical and radar instruments. The data from these networks of complementary instruments have already proven highly valuable by tracing the global-scale phenomena occurring within the ionosphere and thermosphere, for example during the development of specific geomagnetic disturbances. Space missions planned for the next decade, including UARS, to be launched in late 1991, and the Polar Platform missions in the latter part of the decade will include ground-space Correlative Measurement Programmes as an important part of their overall Mission Objectives. Such correlative measurement programmes also provide the opportunities for validation of new 

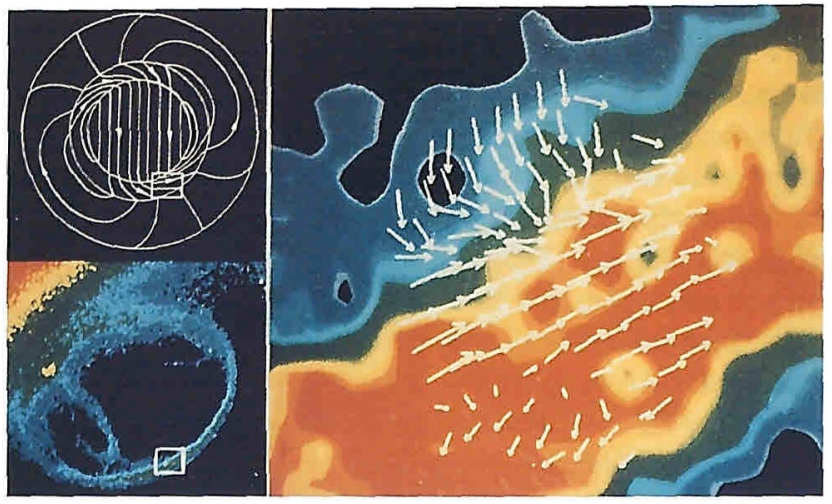

Plate 1. This plate shows a study combining ion velocity distributions obtained from the STARE Radar with a large-scale auroral image from the VIKING satellite (Eos-ref).

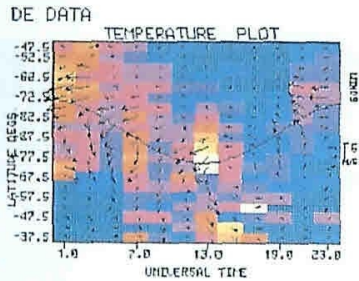

D-DENSITY PLOT

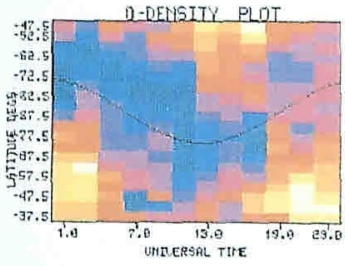

Elec. Fld: EXP.

Elec Dens: DHT

Date: OCT 11 Fia

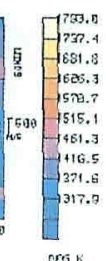

$\cos K$

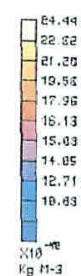

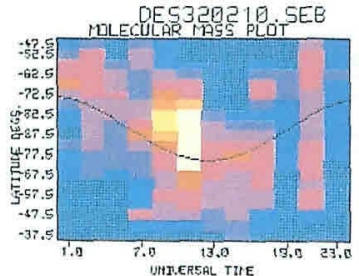
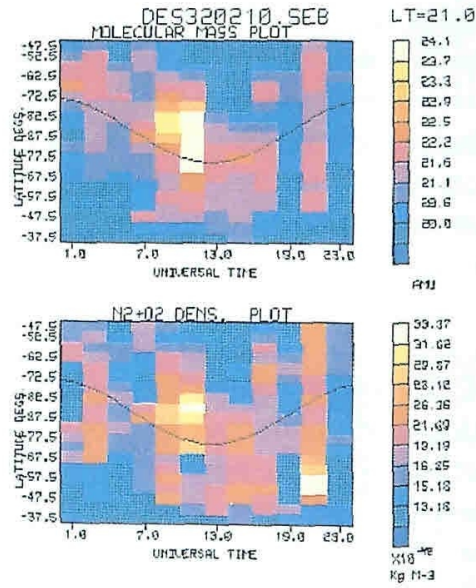

DRTA FROM DE DREITS (WATS \& FPI)

SOUTH POLE PERIGEE EPOCH

Plate 2. This plate shows a statistical analysis of DE-2 WATS, FPI, and NACS data on neutral composition, winds and temperature for the south polar region during October 1981. 


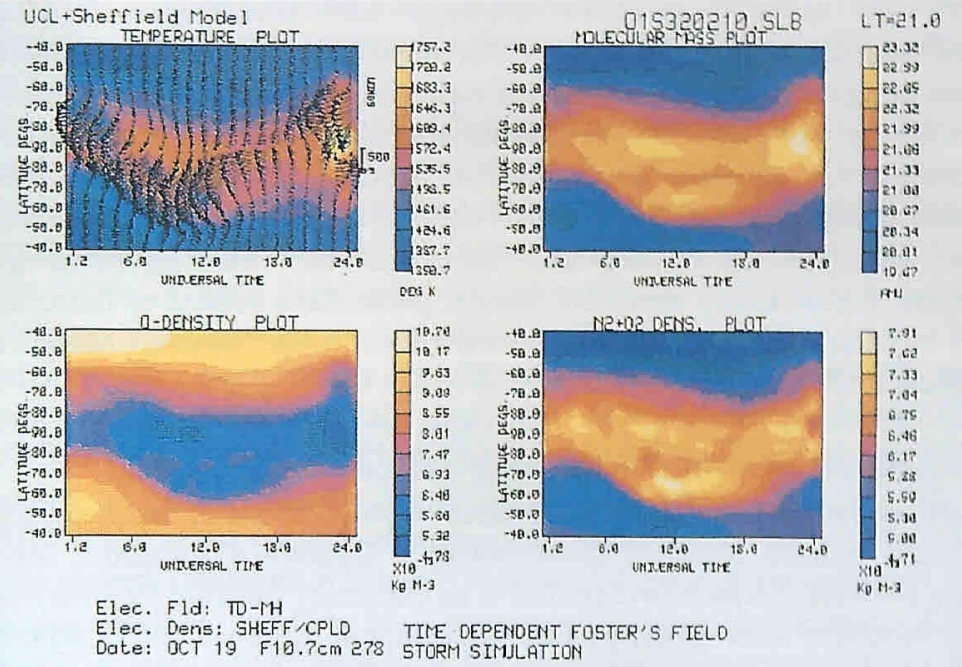

Plate 3. This plate shows the distribution of Neutral composition, winds and temperature for the south polar region during October 1981 as simulated by the coupled ionosphere/thermosphere model, presented in the same format as Plate 2.

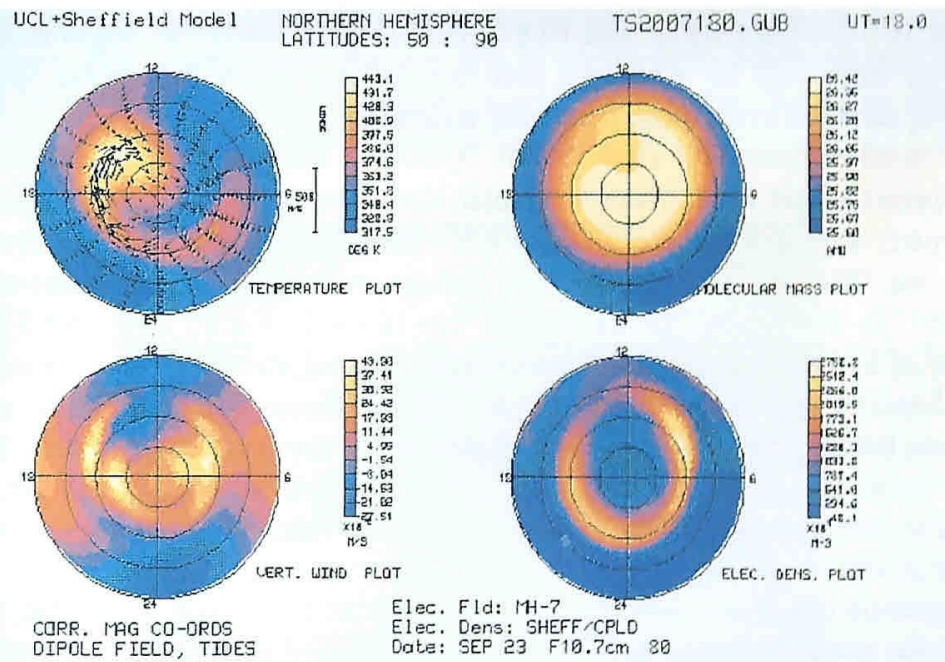

Plate 4. This plate shows the neutral wind, temperature, mean molecular mass, vertical wind, and ion density taken from the UCL/Sheffield coupled ionosphere/thermosphere model, at pressure level 7 , near $120 \mathrm{~km}$, from $50^{\circ} \mathrm{N}$ to $90^{\circ} \mathrm{N}$ latitude, for conditions of low solar activity (F $10.7 \mathrm{~cm}=80$ ), moderate geomagnetic activity $(K p=3)$ and at equinox. Tidal forcing has been included near the lower boundary. 
space techniques, as well as for advanced numerical models. This is important, bearing in mind that the space techniques-perhaps limb-scanning, often sample the atmosphere/ionosphere in a physically different way, as well as by distinct instrument technologies, compared with ground-based or rocket/balloon/aircraft observations.

Space/ground correlative measurements also allow the best features of the distinct sampling from ground and space to be exploited: the continuous coverage of specific regions from ground, compared with the global view obtainable from space. The historical perspective, available from long-term sequences of well calibrated ground-based measurements, is also a very important feature, particularly related to those measurements which may be critical for investigating climatic variability or "Global Change" of regions of the atmosphere or ionosphere.

\subsection{Space-borne observations of atmospheric and ionospheric densities}

We have already referred to the importance of observations of thermospheric winds and global auroral images obtained from NASA's Dynamics Explorer Mission. Other observations from DE-2 which have proved to be extremely valuable for interpreting the state of the thermosphere were obtained from the Neutral Atmosphere Composition Sensor (NACS, CARIGNAN et al., 1981). This instrument, particularly when used with the combined FPI and WATS thermospheric wind data, has provided an invaluable insight into the real workings of the so-called "wind diffusion" mechanism. Briefly, sustained large-scale advective horizontal wind flows, combined with vertical upwelling, in regions of strong and sustained heating, with a lower altitude (and lower velocity return flow) cause a breakdown of static diffusive equilibrium (MAYR and VOLLAND, 1972). As a result, above a region of sustained heating, $F$-region altitudes will show an excess of heavy molecular species, compared with that calculated for the appropriate exospheric temperature assuming static diffusive equilibrium (FULLER-ROWELL and REES, 1983). Conversely, in regions of sustained downwelling, there will be a relative reduction of the heavy molecular species, and a corresponding decrease in the mean molecular weight.

Plate 2 is taken from REES et al. (1985). It shows a statistical analysis of thermospheric neutral temperature and wind, mean molecular mass, atomic oxygen density and molecular nitrogen density as functions of Universal Time and true anomaly (essentially colatitude), obtained by the DE-2 WATS, FPI, and NACS instruments in the south polar region during October 1981. In this period, the DE-2 orbit was in the 22.8 LST to 08.6 LST plane. The combination of high solar insolation, geomagnetic heating and momentum transfer not only forces a characteristic high-latitude wind pattern throughout the middle and upper thermosphere, but also dominates the neutral gas temperature and composition. The southern geographic polar crossings are across the centre of each section of the figure, and the sinusoidal curve represents the closest approach of the satellite, as a function of Universal Time, to the southern geomagnetic pole.

The signature of the geomagnetic polar region is: strongly increased wind, temperature, mean molecular mass, decreased atomic oxygen (and helium) densities, and strongly increased molecular nitrogen density (also of argon). This is a profound composition change, not merely a raising of constant pressure surfaces due to the local temperature increase. Largescale convective overturning of the thermosphere causes much larger compositional changes than those caused by a purely thermal (vertical) expansion of the atmosphere. As geomagnetic activity increases, the magnitude of all of these disturbances increases, and the region affected expands equatorward, following the equatorward expansion of the auroral oval. 
Plate 3 shows the distribution of Neutral composition, winds and temperature for the south polar region during October 1981 as simulated by the UCL/Sheffield coupled ionosphere/thermosphere model, presented in the same format as Plate 2 for comparison with the Dynamics Explorer data.

Such observations of thermospheric composition and temperature by space-borne mass spectrometers have usually been made from relatively low altitude orbits $(300-500 \mathrm{~km}$ at perigee). At higher altitudes, the sensitivity of such instruments is usually inadequate to measure the composition and density of the thermosphere, which decreases rapidly above 500 $\mathrm{km}$, except at times of very high solar and geomagnetic activity. Since a very large proportion of future available space opportunities will utilise spacecraft primarily launched for other purposes, with near-circular orbits between about $600 \mathrm{~km}$ and $850 \mathrm{~km}$ altitude, mass spectrometer methods are not really applicable. As mentioned previously, instruments such as RAIDS (MCCOY et al., 1986) on future NOAA/TIROS spacecraft will remotely sense ionospheric and thermospheric densities, obtaining global pictures of the structural variations which occur as the result of changing solar and geomagnetic activity conditions. It has also been shown (REEs et al., 1987) that useful large-scale maps of changes in thermospheric composition, resulting from geomagnetic storms, can be deduced from global images in the EUV. Figure 11 (Courtesy of J. Craven, Iowa University) shows a bit-out of EUV airglow intensity (130.4 nm, OI) due to the large-scale depletion of thermospheric atomic oxygen which occurred during and following a very large geomagnetic storm. The depletion was a "fossil" of intense heating, upwelling and outflow in a greatly-expanded auroral oval, some 4-6 hours before this image was obtained. The sustained upwelling and outflow created this extended region of substantially reduced atomic oxygen densities at middle and upper thermospheric heights. The upwelling and outflow also enhanced the relative concentration of heavy molecular species.

Another important measurement is that of total air density. Density measurements in the mesosphere and lower thermosphere are in particularly short supply. Resonancefluorescence of molecular oxygen is a particularly useful tracer, for total density in this

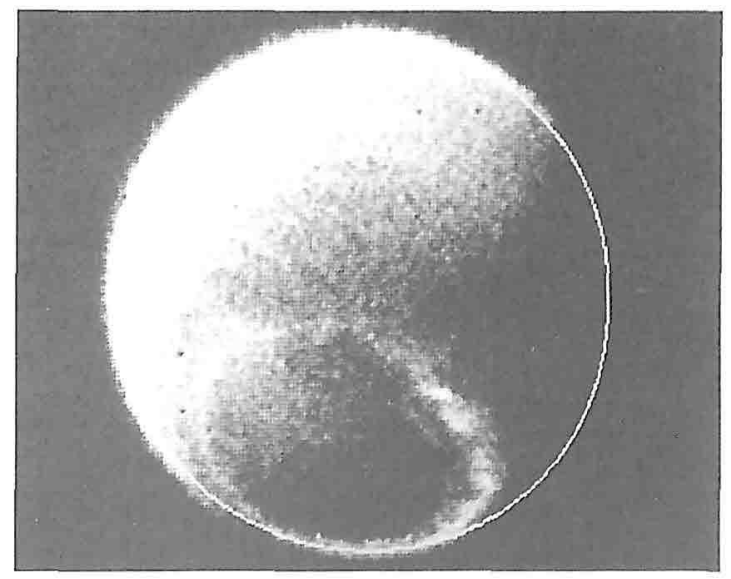

Fig. 11. This figure shows a large-scale depletion of thermospheric atomic oxygen which occurred during and following a very large geomagnetic storm (Courtesy of J. Craven, Iowa University). 
region. Up to about $105 \mathrm{~km}$, molecular oxygen is uniformly mixed and (above about $80 \mathrm{~km}$ ) the Atmospheric Band emissions in the near IR (760 or $860 \mathrm{~nm}$ ) are optically thin. Measurements of band intensity can be readily reduced to derive total oxygen density, and thus total gas density, as a function of altitude. Limb-scanning observations from spacecraft at orbit altitudes of between 400 and around $1000 \mathrm{~km}$ can provide the easiest method of making such observations in a way which is straight-forward to analyse. To make full disk observations of such emissions (i.e. visible and near IR) on the dayside is much more difficult. It would be necessary to reject the intense background illumination due to sunlight back-scattered from the lower atmosphere and surface, against which the useful emissions have a very poor contrast. It is also very difficult to obtain any information on vertical profiles from full-disk observations, although total column density observations of some species may be useful. Table 1 combines a list of target spectral emissions for limb-scan observations for various regions of the mesosphere, thermosphere and ionospheric regions.

To make useful full disk observations of the thermosphere and ionosphere, it is either necessary to restrict the spectral range observed to what is termed the "solar-blind" regioni.e. the FUV and EUV regions, below approx $200 \mathrm{~nm}$, or else to restrict observations to nighttime. At shorter FUV and EUV wavelengths, sunlight does not reach the lower and middle atmosphere. Target emissions generated by resonance fluorescence, excitation by energetic electrons etc., may then be observed against what is essentially a dark background, except for interfering emissions produced by the resonance fluorescence emissions of various

Table 1. Target spectral sources for limb-scan observations: mesosphere, thermosphere and ionosphere.

\begin{tabular}{|c|c|c|c|}
\hline Scientific Objectives & SOURCE & $\begin{array}{c}\text { Wavelength } \\
\mathrm{nm}\end{array}$ & Day/Night \\
\hline \multirow[t]{2}{*}{ Neutral Composition and Temperature } & $\mathrm{N}_{2}$ Airglow & $125-200$ & Day \\
\hline & $\begin{array}{l}\mathrm{O} \text { Airglow } \\
\mathrm{O}_{2} \text { Airglow } \\
\mathrm{O}_{2} \text { Absn. }\end{array}$ & $\begin{array}{l}630,777,845 \\
760,860 \\
760,860\end{array}$ & $\begin{array}{l}\text { Day/Night } \\
\text { Day/Night } \\
\text { Day }\end{array}$ \\
\hline \multirow[t]{2}{*}{ Neutral Wind } & $\begin{array}{l}\mathrm{O} \text { Airglow } \\
\mathrm{O}_{2} \text { Airglow } \\
\mathrm{O}_{2} \text { Absn. }\end{array}$ & $\begin{array}{l}557,630 \\
760,860 \\
760,860\end{array}$ & $\begin{array}{l}\text { Day/Night } \\
\text { Day/Night } \\
\text { Day }\end{array}$ \\
\hline & $\begin{array}{l}\text { OH Airglow } \\
\text { OII Airglow }\end{array}$ & $\begin{array}{l}843 \text { etc. } \\
732\end{array}$ & $\begin{array}{l}\text { Day/Night } \\
\text { Day/Auroral }\end{array}$ \\
\hline $\begin{array}{l}\text { Dayside Electron Density } \\
\text { Nightside Electron Density }\end{array}$ & $\begin{array}{l}\text { OII Dayglow } \\
\mathrm{O}_{2} \text { Recombn }\end{array}$ & $\begin{array}{l}54,83.4 \\
630\end{array}$ & $\begin{array}{l}\text { Day/Auroral } \\
\text { Night }\end{array}$ \\
\hline \multirow[t]{11}{*}{$\begin{array}{l}\text { Energetic Electrons } \\
\text { Minor Species }\end{array}$} & $\begin{array}{l}\mathrm{O} \text { Recombn } \\
\mathrm{N}_{2}, \mathrm{~N}_{2}^{+} \text {Airglow } \\
\mathrm{NO} \text { Airglow }\end{array}$ & $\begin{array}{l}91,130,135,777 \\
125-200 ; 391 \\
200-280(\gamma)\end{array}$ & $\begin{array}{l}\text { Night } \\
\text { Day/Night } \\
\text { Day }\end{array}$ \\
\hline & NO Airglow & $190-240(\delta)$ & Day \\
\hline & $\mathrm{Mg}^{+}$Airglow & 280 & Day \\
\hline & Na Airglow & 589 & Day/Night \\
\hline & He Airglow & 58.4 & Day/Night \\
\hline & OH Airglow & 843 etc. & Day/Night \\
\hline & H Balmer $\alpha$ & 656 & Day/Night \\
\hline & H Balmer $\beta$ & 486 & Day/Night \\
\hline & $\mathrm{H}_{2} \mathrm{O}$ Absn & 720,519 & Day \\
\hline & $\mathrm{O}_{3}$ (Chapuis) & $500-700$ & Day \\
\hline & $\mathrm{O}_{3}$ (absn.) & $270-310$ & Day \\
\hline
\end{tabular}


other atmospheric species. Similarly at nighttime, the competing emissions are weak, and full-disk images of weak airglow emissions may be made. By careful design and fabrication, the Spin Scan Imager of DE-1 (FRANK et al., 1981) was able to image aurorae etc. on the dark hemisphere throughout the visible spectrum, while part of the sunlit earth was also in view. The SSI also excelled in observations at FUV and EUV wavelengths. Table 2 combines a list of target spectral emissions for full disk observations for various regions of the mesosphere, thermosphere and ionospheric regions.

A further method of distinguishing specific emissions against the intense background of scattered sunlight is by using instruments of very high spectral resolution. This method will be discussed in the next section, in connection with instrumentation for measurements of atmospheric and ionospheric dynamics. For determining the small Doppler shifts associated with winds and plasma drifts, very high spectral resolution is mandatory. The high spectral resolution of such instruments provides a high efficiency of rejecting unwanted emissions by virtue of the very narrow spectral transmission bandwidth.

\subsection{Space-borne observations of atmospheric and ionospheric dynamics}

(I) Limb-Scanning

We have seen how it is possible, from the ground, to obtain information on atmospheric winds or ionospheric plasma drifts by optical observations of Doppler shifts either in a sequential scanning mode, or else by the recently-developed field-widened systems (i.e. the DIS or WINDII/MIKADO). The analogies from space are rather similar. The limbscanning method was used by the FPI on Dynamics Explorer, and will be used by the tripleetalon Fabry-Perot interferometer-the High Resolution Doppler Interferometer (HRDI)-on NASA's Upper Atmosphere Research Satellite (to be flown in late 1991). However, the

Table 2. Target spectral sources for disk imaging observations: mesosphere, thermosphere and ionosphere.

\begin{tabular}{llll}
\hline \multicolumn{1}{c}{ Scientific Objectives } & \multicolumn{1}{c}{ SOURCE } & \multicolumn{1}{c}{$\begin{array}{c}\text { Wavelength } \\
\mathrm{nm}\end{array}$} & Day/Night \\
\hline Neutral Composition and Temperature & $\mathrm{N}_{2}$ Airglow & $125-200$ & Day \\
& O Airglow & 130, & Day \\
& O Airglow & $630,777,845$ & Night \\
& $\mathrm{O}_{2}$ Airglow & 760,860 & Night \\
Neutral Wind & O Airglow & 557,630 & Night \\
& O Airglow & 760,860 & Night \\
& OH Airglow & 843 etc. & Night \\
Ion drift velocity & OI Airglow & 732 & Day/Auroral \\
Dayside Electron Density & OII Dayglow & $54,83.4$ & Day/Auroral \\
Nightside Electron Density & $\mathrm{O}_{2}$ Recombn & 630 & Night \\
& O Recombn & $91,130,135,777$ & Night \\
Energetic Electrons & $\mathrm{N}_{2}, \mathrm{~N}_{2}^{+}$Airglow & $125-200 ; 391$ & Day/Night \\
Minor Species & Na Airglow & 589 & Night \\
& He Airglow & 58.4 & Day \\
& OH Airglow & 843 etc. & Night \\
& H Balmer $\alpha$ & 656 & Night \\
& H Balmer $\beta$ & 486 & Night \\
& $\mathrm{H}_{2} \mathrm{O}$ Absn & 720,519 & Day \\
& $\mathrm{O}_{3}$ (Chapuis) & $500-700$ & Day \\
& $\mathrm{O}_{3}$ (absn.) & $270-310$ & Day \\
\hline
\end{tabular}


HRDI instrument will mainly observe winds in the low and middle stratosphere by measuring the Doppler Shift of atmospheric absorption lines (mainly due to molecular oxygen) in the back-scattered solar spectrum, and mesospheric winds by measuring the Doppler Shift of atmospheric emission lines. For limb-scanning instruments, the detailed height structure can be readily determined by making a sequence of observations at discrete altitude steps above the geometric limb. Since the total signal observed from the limb is "contaminated" from regions at higher altitudes (which are in turn sampled), an inversion or deconvolution process is required to obtain the correct vertical profile of wind or temperature. It is possible to obtain a vertical resolution of $1 / 2$ scale height, typically $4 \mathrm{~km}$ in the middle atmosphere and $5-20 \mathrm{~km}$ in the thermosphere. Horizontal resolution is dominated by the limb-view path, typically around $200 \mathrm{~km}$.

WINDII, a second high resolution spectroscopic instrument to fly on UARS, will also measure winds and temperature in a limb-scanning mode. Since it is a field-widened Michelson interferometer (SHEPHERD et al., 1984), it can also image limited spatial regions at the limb, to study spatial structures, and to obtain vertical structure over a limited height region. It is, however, necessary for WINDII to scan in a vertical plane to obtain coverage of the full height range that the instrument will cover in its studies of aeronomic emissions from the upper mesosphere and thermosphere.

To obtain vector wind measurements, both HRDI and WINDII alternately view at $45^{\circ}$ forward and $45^{\circ}$ aft with respect to the normal to the velocity vector of the UARS spacecraft. This means that, from the UARS orbit, the same region at the limb will be observed in the alternate directions with a time-difference of approximately 7 mins. Considering the spatial extent of the region sampled and the atmospheric time constants, for most observations, this small time difference has no importance.

The HRDI and WINDII instruments were somewhat "frozen in time", due to sequential problems and delays in the Space Shuttle Program. Many of the HRDI and WINDII specifications were frozen around 1979, in anticipation of a 1983 launch for UARS. Since then, a large number of technical innovations have been made which have considerably improved the capability of this class of instrument. As an illustration of the present possibilities of the Multi-Etalon Fabry-Perot interferometer, some results will be taken from a "Phase A" study recently carried out on the "Doppler Wind Sensor" (DWS). The DWS was, at the time, being considered for accommodation on the European Polar Platform, part of the NASA/ESA/ISAS "Freedom-Space Station Program" and the Earth Observing System. As an instrument, DWS will observe middle atmosphere $(10$ to $55 \mathrm{~km})$ winds and minor constituent densities via measuring the Doppler Shifts of atmospheric absorption lines (REES et al., 1982; HAYS, 1982; REES, 1985). Above approx 70-75 km, it will measure the Doppler Shifts of the natural emission lines of Hydroxyl, molecular and atomic oxygen, with at least an equivalent capability to WINDII.

As with HRDI, DWS is a triple-etalon Fabry-Perot interferometer. The triple-etalon arrangement (REES, 1985) is required to allow observation of narrow absorption lines within the near-continuum of the spectrum of sunlight back-scattered from the lower atmosphere, by rejecting light in all but a very narrow spectral bandwidth around the target absorption (or emission) line. It can also distinguish between adjacent lines within closely-spaced molecular bands, when observing in emission mode (mesosphere and thermosphere) or absorption mode (upper troposphere and stratosphere). In addition to a large number of minor refinements, there are two major reasons for the considerably-improved observational capability of DWS, compared with HRDI: 
(1) The availability and demonstration of new high performance "broad-band" coatings for the etalons. These permit each of the three etalons to maintain optimum performance over a much-extended spectral range. This avoids severe compromises on individual etalon design. Because of the sequential transmission of light through three etalons, overall instrument transmission was decreased, degrading overall performance.

(2) The recent availability and demonstration of Imaging Photon Detectors with Gallium Arsenide Photocathodes (REEs et al., 1990). The most useful atmospheric absorption lines for middle atmosphere wind measurements result from the absorption bands of molecular oxygen and water vapour. Additional useful spectral targets are due to other minor constituents such as $\mathrm{OH}$ and Ozone. The majority of the most valuable targets occur at wavelengths longer than $600 \mathrm{~nm}$, while several very valuable emission bands occur between 760 and $900 \mathrm{~nm}$. At these near-IR wavelengths, the Gallium Arsenide photocathode has a demonstrated sensitivity advantage of a factor of 5-10 at $760 \mathrm{~nm}((0-0)$ transition of molecular oxygen) and $20-50$ at $860 \mathrm{~nm}((1,0)$ transition of molecular oxygen), compared with the S-25 photocathode technology used in the HRDI detector.

With such major sensitivity advantages, it is possible both to improve the signal to noise ratio (decreasing wind error) and also to decrease the integration times. This allows DWS to "keep ahead" of the spacecraft, and to complete comprehensive limb-scanning observing programmes (Table 3 ) within the $15 \mathrm{sec}$. available, due to the rapid $\left(7-8 \mathrm{kms}^{-1}\right)$ orbital motion of the spacecraft. From a Polar Platform altitude of around $800 \mathrm{~km}$, the target along-track measurement repeat cycle is $200 \mathrm{~km}$ at all altitudes between $10 \mathrm{~km}$ and $400 \mathrm{~km}$. DWS has a 15 second period to complete its "forward look", followed by a $15 \mathrm{~s}$. period to complete its "aft look". This is feasible with the DWS design, and demonstrated etalon coating and detector technology. HRDI, with its much lower overall sensitivity at the wavelengths of critical spectral targets, has to compromise very severely on maximum integration time, and will thus only be able to observe winds etc. at those altitudes at which very strong signal levels are available (below $30 \mathrm{~km}$ in absorption mode). If the DWS can find a launch opportunity on a suitable platform during the next decade, it will make, in combination with a range of other instruments for studying the energetics and chemistry of the middle and upper atmosphere, a very substantial contribution to our knowledge and understanding of the physical and chemical processes, and to the validation of critical numerical models of the atmosphere.

(II) Disk-imaging

We have earlier seen how the DIS concept has been applied to ground-based studies of the middle and upper atmosphere studies during the past decade. Mapping 2-D wind fields, rather than measuring in only a number of specific directions, has led to an improved picture of the complexities of thermospheric wind flows, particularly during geomagnetically disturbed periods at high latitudes. There is a clear distinction between what can be achieved by a limb-scanning instrument such as DWS, from an altitude of $800 \mathrm{~km}$, and what can be achieved by a wide-field imaging instrument such as the DIS. The DIS needs to be placed in a suitable orbit. In principle, an altitude of 3,000 to $15,000 \mathrm{~km}$ is required in order to present the instrument with a view of a substantial part of the auroral oval and polar cap. From such an altitude, a DIS would also be able to view large mid-latitude or equatorial regions, at different phases of its orbit (preferably near-polar). Figure 12 shows a view of the auroral oval, obtained by the SSI on DE-2, which would provide an ideal geometry for mapping the ion and neutral flows over the auroral oval and polar cap. 
Table 3. Limb-scanning observing programme for wind and temperature measurements. The following scenario is representative of the calculated performance of an instrument such as the DOPPLER WIND SENSOR, observing each spectral target and each atmospheric region. The limb-scan observing sequence is based on a $200 \mathrm{~km}$ (30 s) sample repeat pattern. The calculations are conservative, based on demonstrated measurements on OI $630 \mathrm{~nm}$ nightglow and on the $\mathrm{OH}$ near-IR Meinel emissions, using a ground-based instrument (REES et al., 1990-GRL).

Scenario 1: Day: General Purpose:

\begin{tabular}{|c|c|c|c|c|c|c|c|}
\hline $\begin{array}{l}\text { Height Levels } \\
(\mathrm{km})\end{array}$ & $\begin{array}{l}\text { No of } \\
\text { Steps }\end{array}$ & Species & $\begin{array}{c}\text { Wave- } \\
\text { length } \\
\mathrm{nm}\end{array}$ & $\begin{array}{l}\text { Total } \\
\text { Time } \\
\text { (sec) }\end{array}$ & $\begin{array}{c}\text { Filter } \\
\text { Change }\end{array}$ & $\begin{array}{c}\text { Elapsed } \\
\text { Time } \\
(\mathrm{sec})\end{array}$ & $\begin{array}{l}\text { Wind } \\
\text { Error } \\
\mathrm{Ms}^{-1} \\
\end{array}$ \\
\hline $10,14,18$ & 3 & $\mathrm{O}_{2}(\mathrm{absn})$ & 688 & 0.4 & $\mathrm{~N}$ & 0.4 & 3 \\
\hline $20,24,28$ & 3 & $\mathrm{O}_{2}$ (absn) & 688 & 0.6 & $\mathrm{Y}$ & 1.0 & 3 \\
\hline Filter Change & & & & & 0.5 & 1.5 & \\
\hline $30,34,38$ & 3 & $\mathrm{O}_{2}$ (absn) & 763 & 0.7 & $\mathrm{~N}$ & 2.2 & 3 \\
\hline $40,44,48$ & 3 & $\mathrm{O}_{2}(\mathrm{absn})$ & 763 & 0.9 & $\mathrm{~N}$ & 3.1 & 5 \\
\hline $50,54,58$ & 3 & $\mathrm{O}_{2}$ (absn) & 763 & 3.6 & $\mathrm{~N}$ & 6.7 & 5 \\
\hline $70,74,78$ & 3 & $\mathrm{O}_{2}(\mathrm{emmn})$ & 763 & 0.4 & $\mathrm{~N}$ & 7.1 & 5 \\
\hline $80,84,88$ & 3 & $\mathrm{O}_{2}(\mathrm{emmn})$ & 763 & 0.3 & $\mathrm{~N}$ & 7.4 & 5 \\
\hline 90,96 & 2 & $\mathrm{O}_{2}(\mathrm{emmn})$ & 763 & 0.2 & $\mathrm{~N}$ & 7.6 & 5 \\
\hline 100,106 & 2 & $\mathrm{O}_{2}(\mathrm{emmn})$ & 763 & 0.2 & $\mathrm{~N}$ & 7.8 & 10 \\
\hline 110,116 & 2 & $\mathrm{O}_{2}(\mathrm{emmn})$ & 763 & 0.2 & $\mathrm{~N}$ & 8.0 & 10 \\
\hline 120,126 & 2 & $\mathrm{O}_{2}(\mathrm{emmn})$ & 763 & 1.5 & $\mathrm{~N}$ & 9.5 & 10 \\
\hline 130,136 & 2 & $\mathrm{O}_{2}(\mathrm{emmn})$ & 763 & 2.5 & $\mathrm{Y}$ & 12.0 & 10 \\
\hline Filter Change & & & & & 0.5 & 12.5 & \\
\hline 150 & 1 & $\mathrm{O}(\mathrm{emmn})$ & 557 & 0.1 & $\mathrm{~N}$ & 12.6 & 10 \\
\hline 170,195 & 2 & $\mathrm{O}(\mathrm{emmn})$ & 557 & 0.1 & $\mathrm{Y}$ & 12.7 & 10 \\
\hline Filter Change & & & & & 0.5 & 13.2 & \\
\hline 200,225 & 2 & $\mathrm{O}(\mathrm{emmn})$ & 630 & 0.1 & $\mathrm{~N}$ & 13.3 & 10 \\
\hline 250,275 & 2 & $\mathrm{O}(\mathrm{emmn})$ & 630 & 0.1 & $\mathrm{~N}$ & 13.4 & 10 \\
\hline 300,325 & 2 & $\mathrm{O}(\mathrm{emmn})$ & 630 & 0.1 & $\mathrm{~N}$ & 13.5 & 10 \\
\hline 350,375 & 2 & $\mathrm{O}(\mathrm{emmn})$ & 630 & 0.1 & $\mathrm{~N}$ & 13.6 & 10 \\
\hline 400,425 & 2 & $\mathrm{O}(\mathrm{emmn})$ & 630 & 0.2 & $\mathrm{~N}$ & 13.8 & 10 \\
\hline 450 & 1 & $\mathrm{O}(\mathrm{emmn})$ & 630 & 0.2 & $\mathrm{Y}$ & 14.0 & 10 \\
\hline $\begin{array}{l}\text { Total number of } \\
\text { steps }\end{array}$ & 45 & & & & $\begin{array}{l}\text { Total } \\
\text { Time }\end{array}$ & $14.0 \mathrm{sec}$. & \\
\hline Reset time & 1 & & & & & $1.0 \mathrm{sec}$. & \\
\hline
\end{tabular}

N.B. Last step requires a filter change and saw-tooth $(1 \mathrm{sec})$ to reset for start of the next upward scan in the next (forward/backward) direction.

The DIS has to observe the atmosphere in a slant view, when line-of-sight Doppler shifts are a substantial fraction of the total (near-horizontal) wind or ion flow velocity. Instruments such as HRDI or DWS view the limb by alternating in orthogonal directions $45^{\circ}$ forward and aft of the normal to the spacecraft velocity vector. They measure the two orthogonal wind components with a small (5-10 min) time separation, as the spacecraft moves along its low-earth-orbit, DIS, in contrast, may not remeasure the flow from a convenient "orthogonal" position. Determination of the 2-D vector wind and ion flow patterns requires analysis methods similar to those currently in use to determine 2-D wind flows from the ground-based DIS (see Subsection 2.2). For the G.B. DIS, exhaustive tests 


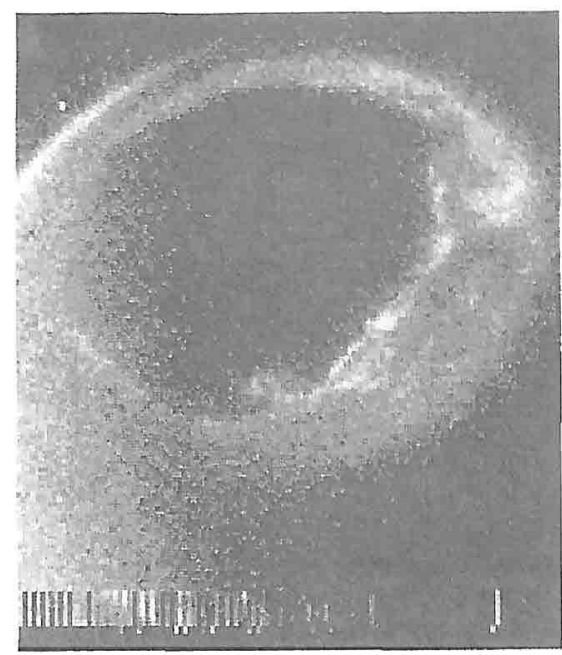

UCL ATTIOSPHERIC PHYSICS DYNAMIC EXPLORER AURORAL. IMAGE COURTESY UNIUERSITY OF IOLH

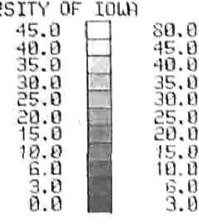

RALJ

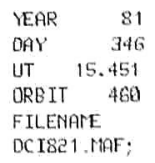

Fig. 12. This figure shows a view of the northern auroral oval, obtained by the SSI on DE-2, which would provide an ideal geometry for mapping the ion and neutral flows over the auroral oval and polar cap usig a space-borne Doppler Imaging System (Courtesy of J. Craven, lowa University).

have demonstrated the robustness of the methods and solutions used. The space-borne version also has to correct for the line-of-sight velocity of the spacecraft, resolved along the viewing direction. This, of course, changes very significantly over the wide field of view of the DIS (as in Fig. 12).

For observations of the dynamics of the mesosphere, thermosphere and ionosphere, and on the night-side and in the winter polar cap, the DIS can be used in the form of a fieldwidened single-etalon Fabry-Perot interferometer, essentially identical to the ground-based version, except that the front-end "wide-angle" optics have to match the specific requirements for field of view, given the instrument parameters and orbit altitude. Figure 13 is an image obtained from the SSI of DE-1 on March 13, 1989, during one of the largest geomagnetic disturbances on record (ALLEN et al., 1989). It shows the disturbed enormously expanded and very active auroral oval and polar cap from the perspective required by a DIS. The DIS would be able to map 2-D patterns of thermospheric wind flow and the convective ion flows throughout this entire region. Figure 12 provides an excellent perspective of the region of auroral precipitation at the height of this disturbed period. The series of images obtained by SSI also depict the evolution of auroral precipitation during the event. However, the information available about the magnetospheric convection during this very interesting disturbance was very limited: the peak cross-polar cap potential reached $400 \mathrm{KV}$, approximately 10 times the "quiet" value. However, there is no description of convection patterns (or of the resulting winds etc.), inside or outside the regions of intense precipitation. Neither do we understand the temporal evolution. A space-borne DIS would have been able to resolve details of the convection velocity distribution with the same spatial resolution displayed in Figs. 12 and 13.

The technical problems of making a DIS instrument work in the "solar blind" spectral region, i.e. below $200 \mathrm{~nm}$, have not yet been solved. In the visible, near-UV and near-IR, a 


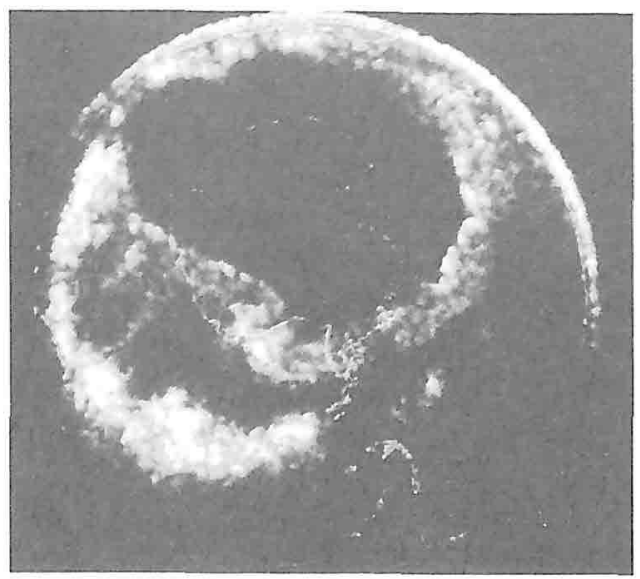

Fig. 13. This figure shows an image obtained from the SSI of DE-1 on March 13, 1989, during one of the largest geomagnetic disturbances on record (ALLEN et al., 1989).

triple-etalon FPI could largely reject the strong but unwanted solar background, permitting dayside observations. However, the problems of converting the triple-etalon FPI to a fieldwidened equivalent have not yet been solved. Thus, for the moment, it is not feasible to use an instrument of the DIS type for wind and ion flow observations on the dayside, against the sunlit hemisphere. If the full potential of these powerful techniques are to be exploited, there will always be a need for the combination of limb-scanning instruments, operating at altitudes between 400 and about $800 \mathrm{~km}$, and imaging instruments on spacecraft which spend some time in orbits above $2000-5000 \mathrm{~km}$. The wide-field imaging data from the latter, covering the night side and winter polar regions, need to be merged with the dayside data only obtainable from limb-scanning instruments. Additionally, these can provide better height resolution, essential for some studies, by virtue of the limb-scanning technique, even when observing emissions from large vertical regions.

\section{Advanced and Coupled Models of the Magnetosphere/Thermosphere/Ionosphere}

The development of the UCL Three Dimensional Thermospheric Model is well documented in previous publications (FULLER-ROwELL and REES, 1980, 1983), as is the Sheffield ionospheric model (QUEGAN et al., 1982, 1986). The development of the fully coupled ionosphere/thermosphere model has been reported by QUEGAN et al. (1982) and Fuller-Rowell et al. (1984), Fuller-Rowell et al. (1987) and by REES and FullerRowell $(1987 \mathrm{a}, \mathrm{b})$. These models will not be discussed in detail here, and the reader is referred to the papers cited above, and to the equivalent series of papers by Roble, Dickinson and colleagues, describing the NCAR TIGCM.

In the general sense, the future major developments of coupled ionosphere/thermosphere models are only in three areas: (1) Improved empirical models of direct energy and momentum inputs; (2) Direct coupling to models describing the middle atmosphere; (3) Direct coupling to magnetospheric models. 
The first of these has been dealt with throughout the review: the required advances in instrumentation techniques and the provision of new space opportunities by Space Agencies which can, in combination, provide the detailed and time-dependent empirical models of energy and momentum sources.

The second of these areas is in the process of further development, and exciting new advances are likely within the next 2-4 years. Until now, the only method of including the effects of stratospheric and mesospheric disturbances into models of the ionosphere and thermosphere has been by utilising techniques developed by FESEN et al. (1986) for the NCAR TGCM, and by PARISH et al. (1990) for the UCL/Sheffield coupled ionosphere/thermosphere Model. In this approach, a function is introduced in the lowest levels of the numerical model which introduces a self-consistent perturbation of wind, temperature and density, corresponding to the potential function (Hough Function) of a specific tidal mode, or series of tidal modes. The approach gets around the requirement for self-consistent computation from the much lower levels of the atmosphere (surface to $50 \mathrm{~km}$ ) where solar radiation is absorbed by water vapour and ozone, producing the heating which generates the principle propagating tidal waves.

Although this approach cannot (as yet) emulate the complex response of the middle atmosphere to combined gravity, tidal and planetary waves, it is quite capable of generating realistic and self-consistent propagating tidal disturbances within the lower thermosphere. Individual tidal modes interact with each-other, and with the in-situ thermospheric disturbances. This method produces highly interesting results (FULLER-ROWELL et al., 1991b), and it can produce an estimate of the amplitude and phases of tides observed during coordinated observing programmes. It is thus particularly useful for interpreting the data from large-scale coordinated campaigns involving many ground-based optical/radar stations. However, the real structure of the mesosphere is complex, and the propagation characteristics of tides through the lower and middle atmosphere is highly dependent on meteorological variations as are, in fact, the sources of the propagating tidal waves themselves.

Fortunately, in the same period that the coupled ionosphere/thermosphere models have been developed, sophisticated middle atmosphere models have been developed at a very rapid rate. Initiatives such as the UK University Global Atmospheric Modelling Project (UGAMP, GRAY et al., 1991), and equivalent initiatives in the USA, have produced multi-level models extending from the troposphere into the mesosphere. These models include meteorological and geographical forcing at the lower levels, and a complex treatment of radiation, chemistry and dynamics in the stratosphere and mesosphere.

It is planned to couple the UGAMP model with the UCL/Sheffield model, via the initial development of an extension region to each model, producing an overlap region of 3-4 scale heights. Data exchange between the two models will then be feasible for "quasi-steady state" simulations. These will be followed by more realistic simulations including the effects of day by day variability of mesospheric planetary, tidal and gravity wave forcing, and corresponding upper mesospheric and lower thermospheric responses to external (lower atmosphere and solar/magnetospheric) variations.

A later stage of development will be to find a practical technique of merging these codes. It should be possible to conduct experiments where the middle atmosphere and upper atmosphere models are running in parallel on the same machine. Data can then be exchanged between the middle atmosphere and upper atmosphere models on a regular basis (say 1 per 30 mins). Stability criteria indicate that it may not be practical to fully merge the code of a sophisticated lower/middle atmosphere model with that of a comparably advanced 
ionosphere/thermosphere model, which might otherwise achieve the level of merging which currently exists for ionosphere/thermosphere models. Even the first stage, running the programmes in parallel, would require significant advances in computing power and disk storage compared with the capability of currently available super-computers.

In the third area, the first experiments have been performed recently by interchanging input and output data sets between the UCL/Sheffield model and the RICE Magnetospheric Convection Model. Evaluation of this initial work has been reported by FULLER-ROWELL et al. (1988) and FULLER-ROWELL (1990). As was discussed earlier (i.e. Subsection 2.4), the present ionosphere/thermosphere models assume that the simple empirical magnetospheric models of convection and precipitation used as inputs are unaffected by any induced changes in the ionosphere or thermosphere. It is also assumed that they are unchanged, by underlying variations of ionospheric conductivity, resulting from UT and seasonal changes of solar photoionisation, or of EMF, resulting from lower thermospheric winds of tidal or planetaryscale origin. Each or these assumptions is suspect, at least under certain conditions. Within numerical models of the atmosphere, a number of important sub-grid scale processes such as gravity waves and eddy turbulence have to be parameterised, and are not treated explicitly. Similarly, many sub-grid scale magnetospheric processes have to be parameterised in magnetospheric models. The RICE magnetospheric convection model, with its own simplifications of magnetospheric processes and phenomena, calculates the zero order ionospheric response and feedback to precipitation. However, it does not account for conductivity changes resulting from solar photoionisation effects, or for ionospheric dynamo EMF from the initial or modified neutral wind dynamo etc.

\section{Lower Thermosphere Response to Lower Atmosphere and Magnetosphere Forcing}

As an example of the present "limits" of modelling, we will consider the response of the lower thermosphere and ionosphere to the combination of middle atmosphere tidal forcing and magnetospheric forcing. It has been notoriously difficult to monitor the lower thermosphere observationally, although the ISR can probe the plasma environment most effectively. At pressure level 7 in the UCL/Sheffield ionosphere/thermosphere model (roughly $120 \mathrm{~km}$ ), the neutral wind response to magnetospheric forcing (ion drag and Joule/particle heating) is roughly $50-70 \%$ of that induced in the upper thermosphere. This is due to the different balances of Coriolis, pressure gradient, and ion-drag forces acting on the neutrals. In-situ solar heating and the effects of tides propagating from the lower atmosphere are also important, particularly so during quiet geomagnetic periods.

Plate 4 shows the neutral wind, temperature, mean molecular mass, vertical wind, and ion density at pressure level 7 , near $120 \mathrm{~km}$, from $50^{\circ} \mathrm{N}$ to $90^{\circ} \mathrm{N}$ latitude, for conditions of low solar activity $(\mathrm{F} 10.7 \mathrm{~cm}=80)$, moderate geomagnetic activity $(K p=3)$ and at equinox. Tidal forcing has been included near the model's lower boundary. The tidal forcing from the middle atmosphere generated wind components of order $50 \mathrm{~ms}^{-1}$, which are not particularly apparent at high-latitudes at moderate levels of geomagnetic activity. However, the tidal influence can be seen in the mid-latitude regions, in both the temperature and vertical wind plots, as a semi-diurnal variation. At pressure level 7 , the ion density distribution is dominated by the distribution of auroral (electron) precipitation. The auroral oval has an elliptical boundary, due to the "distortion" of the IGRF magnetic field model. Typical $E$ region ion densities of between 2 and $3 \cdot 10^{11} \mathrm{~m}^{-3}$ occur in the auroral oval. Outside the auroral oval, solar photo-ionisation generates ion densities a factor 5 lower than those in the 
auroral oval. A strong clockwise vortex is generated in the wind circulation in the dusk auroral oval, with peak winds of around $200 \mathrm{~ms}^{-1}$.

Interactions between the polar ionosphere and the magnetosphere have not been considered in a self-consistent way in this simulation. The magnetosphere has assumed to be a zero-resistance source of the FAC required to match the Pedersen currents produced by the applied potential. The ionospheric conductivity is produced by the combination of auroral precipitation and solar photoionisation sources. Thermosphere/ionosphere interactions, the conductivity changes and localised regions where the back-EMF may be as high as 5-10 $\mathrm{mVm}^{-1}$ due to the induced neutral wind dynamo, will cause considerable modulation of the ionospheric electric currents. Under some conditions, the magnetosphere may respond to the ionospheric/thermospheric feedback by changes in the morphology of the external convection electric field, the FAC and energetic particle precipitation.

\section{Conclusions}

The past decade has seen a major improvement in the quality and quantity of experimental data describing the thermosphere and ionosphere and their response to magnetospheric forcing. This has been matched by the development of self-consistent coupled models of the ionosphere/thermosphere system. A clear picture of the distinction between the solar and geomagnetic forcing processes has emerged from the combined data sets available from spacecraft such as the Dynamics Explorers, and from ground-based radar and optical observations of the polar thermosphere. A first experimental view of the strong coupling between the thermosphere and ionosphere has also emerged from these combined data new sets.

We can now simulate realistically the response of the combined system to magnetospheric forcing, and also investigate some of the feedback processes between the two components. Current models can be used to understand and interpret diverse experimental observations, and provide the framework for evaluating phenomena which are as yet not well understood.

Over the next several years, new experimental data will become available from coordinated ground-based campaigns. Hopefully, by the end of the decade, we will see contributions from new space missions. Space-borne and ground-based experimental techniques which are now mature will be able to provide graphic large-scale images of the structure and dynamics of the ionosphere and thermosphere. These will greatly extend our understanding of the inter-relationships between precipitation, plasma convection and the subsequent response of the polar ionosphere and thermosphere. These new data will also test the validity of simplified assumptions of current models, leading to their improvement.

The patterns of magnetospheric forcing used in present models are too simplified and averaged in time and space. The development of techniques enabling imaging of polar plasma convection patterns, available jointly with images of particle precipitation and energy deposition, will have a dramatic impact. Future models will be able to include the important effects of short period, smaller scale, variations in forcing.

Two further advances in coupled models will also have very important consequences. Firstly, coupled middle atmosphere-ionosphere/thermosphere models will be able to fully account for energy and momentum exchange between the middle and upper atmosphere, as well as for the vertical mixing of important species such as ozone, hydroxyl, atomic oxygen and nitric oxide. Secondly, the further development of coupled magnetosphere- 
ionosphere/thermosphere models will permit the important feedback processes due to changes in conductivity and back-EMF to be evaluated.

The next decade will prove to be extremely exciting: new space opportunities are needed, to establish and exploit the potential of novel instruments. Maintaining and extending ground-based optical and radar networks, and the development of the next generation of coupled numerical models, will stretch available resources, and lead to a major increase in knowledge of the thermosphere and ionosphere.

This research was supported in part by grants from the UK Science and Engineering Research Council.

\section{REFERENCES}

AlCAYDE, D. and J. FonTANARI, Neutral temperature and winds from EISCAT GP-3 observations, $J$. Atmos. Terr. Phys., 48, 931-947, 1986.

AlCAYde, D, G. CAUdal, and J. Fontanari, Convection electric fields and electrostatic potential over $60^{\circ}<$ $\Lambda<72^{\circ}$ invariant latitude observed with the European incoherent scatter facility, 1 . Initial results, $J$. Geophys. Res., 91, 233-247, 1986.

Allen, J., H. Sauer, L. Frank, and P. Reiff, Effects of the March 1989 Solar Activity, Eos, Trans. Am. Geophys. Union, 70, 46, 1479, 1989.

Armstrong, E. B., Doppler shifts in the wavelength of the OI 6300 line in the night airglow, Planet. Space Sci., 17, 957-974, 1969.

Baker, K. B., R. A. Greenwald, J. M. Ruohoniemi, J. R. Dudeney, M. Pinnock, N. Mattin, and J. M. LeONARD, EOS Transactions, AGU, Vol. 70, No. 34, August 22, 1989.

Banks, P. M. and G. Kockarts, Aeronomy, Academic Press, New York, 1973.

BAtTen, S., D. REes, D. WADE, and A. SteEN, Observations of thermospheric neutral winds by the UCL Doppler imaging system at Kiruna in northern Scandinavia, J. Atmos. Terr. Phys., 50, No. 10/11, 861-888, 1988.

Carignan, G. R., B. P. Block, J. C. Maurer, A. E. Hedin, C. A. Reber, and N. W. Spencer, The Neutral Mass Spectrometer on the Dynamics Explorer, Space Sci. Instrum., 5, 429-441, 1981.

COLE, K. D., Joule heating of the upper atmosphere, Aust. J. Phys., 15, 223-235, 1962.

Cole, K. D., Electrodynamic heating and movement of the thermosphere, Planet. Space Sci., 19, 59-75, 1971.

Fesen, C. G., R. E. Dickinson, and R. G. Roble, Simulations of the thermospheric tides at equinox with the National Center for Atmospheric Research Thermospheric General Circulation Model, J. Geophys. Res., 91, 4471-4489, 1986.

Foster, J. C., J. M. Holt, R. G. Musgrove, and D. S. Evans, Ionospheric convection associated with discrete levels of particle precipitation, Geophys. Res. Lett., 13, 656-649, 1986.

Frank, L. A., J. D. Craven, K. L. Ackerson, M. R. English, R. H. Eather, and R. L. Carovillano, Global auroral imaging instrumentation for the Dynamics Explorer mission, Space Sci. Inst., 5, 369-393, 1981.

Fuller-Rowell, T. J. and D. ReEs, A three-dimensional, time-dependent, global model of the thermosphere, J. Atmos. Sci., 37, 2545-2567, 1980.

Fuller-Rowell, T. J. and D. Rees, Derivation of a conservative equation for mean molecular weight for a two constituent gas within a three-dimensional, time-dependent model of the thermosphere, Planet. Space Sci., 31, 1209-1222, 1983.

Fuller-Rowell, T. J., D. Rees, S. Quegan, G. J. Balley, and R. J. Moffett, The effect of realistic conductivities on the high-latitude thermospheric circulation, Planet. Space Sci., 32, 469-480, 1984.

Fuller-Rowell, T. J. and D. S. Evans, Height-integrated Pedersen and Hall conductivity patterns inferred from the TIROS-NOAA satellite data, J. Geophys. Res., 92, 7606-7618, 1987. 
Fuller-Rowell, T. J., S. Quegan, D. ReEs, R. J. MOFFeTt, and G. J. BAILEY, Interactions between neutral thermospheric composition and the polar ionosphere using a coupled ionosphere-thermosphere model, J. Geophys. Res., 92, 7744-7748, 1987.

FULLER-Rowell, T. J., Initial Simulations of Magnetosphere-Thermosphere Feedback using a Coupled Numerical Model. COSPAR 1990, The Hague (INV. MC 8).

Fuller-Rowell, T. J., D. Rees, S. Quegan, R. J. Moffett, and G. J. Bailey, Simulations of the seasonal and universal time variations of the high-latitude thermosphere and ionosphere using a coupled, three dimensional model, PAGEOPH, Vol. 127, No. 2/3, 1988.

Fuller-Rowell, T. J., D. Rees, H. Rishbeth, A. G. Burns, T. L. Killeen, and R. G. Roble, Modelling of composition changes during $F$-region storm: a reassessment, J. Atmos. Terr. Phys., 53 (6/7), 541$550,1991 \mathrm{a}$.

Fuller-Rowell, T. J., D. Rees, H. Parish, T. S. Virdi, P. J. S. Williams, and R. M. Johnson, Lower Thermosphere Coupling Study: Comparison of observations with predictions of the UCL-Sheffield Thermosphere/Ionosphere model, J. Geophys. Res., 96, A2, 1181-1202, $1991 \mathrm{~b}$.

Gray, L. J., M. Blackburn, M. P. Chipperfield, J. D. Haigh, D. Jackson, K. P. Shine, J. Thuburn, and W. ZhoNG, First results from a 3-Dimensional Middle Atmosphere Model, Adv. Space Res., 1991 (in press).

Hardy, D. A., M. S. Gussenhoven, and E. Holeman, A statistical model of auroral electron precipitation, $J$. Geophys. Res., 90, 4229-4248, 1985.

Hays, P. B., J. W. Meriwether, and R. G. Roble, Nighttime thermospheric winds at high latitudes, J. Geophys. Res., 84, 1905-1913, 1979.

Hays, P. B., T. L. Killeen, and B. C. Kennedy, The Fabry-Perot interferometer on Dynamics Explorer, Space Sci. Inst., 5, 395-416, 1981.

HAYS, P. B., High-resolution optical measurements of atmospheric winds from space. 1: Lower atmosphere molecular absorption, Appl. Opt., 21, 1136, 1982.

Hays, P. B., T. L. Killeen, N. W. Spencer, L. E. Wharton, R. G. Roble, B. A. Emery, T. J. FullerRowell, D. Rees, L. A. Frank, and J. D. Craven, Observations of the Dynamics of the Polar Thermosphere, J. Geophys. Res., 89, 5547-5612, 1984.

Heelis, R. A., W. B. Hanson, C. R. Lippincott, D. R. Zuccaro, L. H. Harmon, B. J. Holt, J. E. Doherty, and R. A. Power, The ion drift meter for Dynamics Explorer-B, Space Sci. Instrum., 5, 511-521, 1981.

Heppner, J. P., Empirical Models of High Latitude Electric Field, J. Geophys. Res., 82, 1115-1125, 1977.

Heppner, J. P. and N. C. MAYNARd, Empirical High-Latitude Electric Field Models, J. Geophys. Res., 92, 4467-4490, 1987.

Hernandez, G., Fabry-Perot Interferometers, Cambridge University Press, Cambridge, 1986.

HeRnAndez, G. and T. L. Kllleen, Optical measurements of winds and temperatures in the upper atmosphere, in Cospar International Reference Atmosphere 1986 Vol. 1, Upper Atmospheric Models, edited by D. Rees, Pergamon Press, 1988.

Hoffman, R. A. and E. R. Schmerling, Dynamic Explorer Program: an overview Dynamic Explorer, Space Sci. Instrum., 5, 345-348, 1981.

Hoffman, R. A., M. Sigiura, and N. C. Maynard, Current carriers for the field-aligned current system, $A d v$. Space Res., 5, 109-126, 1985.

JOHN HOPKINS UNIVERSITY, APL: Technical Digest Vol. 5, No. 2. April-June, 1984.

Killeen, T. L., P. B. Hays, N. W. Spencer, and L. E. Wharton, Neutral winds in the polar thermosphere as measured from Dynamics Explorer, Adv. Space Res., 2, No. 10, 133-136, 1983.

Killeen, T. L., R. R. Heelis, P. B. Hays, N. W. Spencer, and W. B. Hanson, Neutral motions in the polar thermosphere for northward interplanetary magnetic field, Geophys. Res. Lett., 12, 159-162, 1985.

Killeen, T. L., R. W. Smith, N. W. Spencer, J. W. Meriwether, D. Rees, G. Hernandez, P. B. Hays, L. L. Cogger, D. P. Sipler, M. A. Biondi, and C. A. TePley, Mean neutral circulation in the winter polar $F$. region, J. Geophys. Res., 91, 1633-1649, 1986.

Killeen, T. L., J. D. Craven, L. A. Frank, J.-J. Ponthieu, N. W. Spencer, R. A. Heelis, L. H. Brace, R. G. Roble, P. B. Hays, and G. R. CARIGnan, On the relationship between the dynamics of the polar thermosphere and the morphology of the aurora: Global scale observations from Dynamics Explorers 1 and 2, J. Geophys. Res., 93, 2675-2692, 1988. 
Knipp, D. J., A. D. Richmond, G. Crowley, O. de la Beaujardiere, E. Eris-Christensen, D. S. Evans, J. C. Foster, I. W. MCCreA, F. J. RICH, and J. A. WALDOCK, Electrodynamic Patterns for September 19, 1984, J. Geophys. Res., 94, 16913-16923, 1989.

Krehbiel, J. P., L. H. Brace, R. F. Theis, W. H. Pinkus, and R. B. Kaplan, The Dynamics Explorer Langmuir probe instrument, Space Sci. Instrum., 5, 493-502, 1981.

McCoy, R. P., K. D. Wolfram, R. R. Meier, L. J. Paxton, D. D. Cleary, D. K. Prinz, D. E. Anderson, JR. A. B. Christensen, J. Pranke, G. G. Sivjee, and D. Kayser, The Remote Atmospheric and Ionospheric Detection System, SPIE, 687, 142-149, 1986.

Manson, A. H. and G. E. Meek, J. Atmos. Terr. Phys., 43, 35-44, 1980.

MAYR, H. G. and H. Volland, Theoretical model for the latitude dependence of the thermospheric annual and semi-annual variations, J. Geophys. Res., 77, 6774-6790, 1972.

Meriwether, J. W. Jr., Observations of thermospheric dynamics from ground and space, Radio Sci., 18, 1035-1052, 1983.

Meriwether, J. W. Jr., P. Shih, T. L. Killeen, V. B. Wickwar, and R. G. Roble, Nighttime thermospheric winds over Sondre Stromfjord, Greenland, Geophys. Res. Lett., 11, 931-934, 1984.

Meriwether, J. W., M. A. Biondi, and D. N. Anderson, Equatorial airglow depletions induced by thermospheric winds, Geophys. Res. Lett., 12, 487-490, 1985.

Parish, H., T. J. Fuller-Rowell, D. Rees, T. S. Virdi, and P. J. S. Williams, Numerical simulations of the seasonal response of the thermosphere to propagating tides, Adv. Space Res., 10, 287-291, 1990.

Quegan, S., G. J. Bailey, R. J. Moffett, R. A. Heelis, T. J. Fuller-Rowell, D. Rees, and R. W. Spiro, Theoretical study of the distribution of ionization in the high-latitude ionosphere and the plasmasphere: First results on the mid-latitude trough and the light-ion trough, J. Atmos. Terr. Phys., 44, 619-640, 1982.

Quegan, S., G. J. Bailey, R. J. Moffett, L. C. Wilkinson, Universal time effects on the plsma convection in the geomagnetic frame, J. Atmos. Terr. Phys., 48, 25-40, 1986.

Rees, D., T. J. Fuller-Rowell, and R. W. SMith, Measurements of high-latitude thermospheric winds by rocket and ground-based techniques and their interpretation using a three-dimensional time-dependent dynamical model, Planet. Space Sci., 28, 919-932, 1980.

Rees, D., I. McWhirter, P. A. Rounce, and F. E. BArlow, Miniature Imaging photon detectors II: Devices with transparent photocathodes, J. Phys. Sci. Instrum., 14, 229-233, 1981.

Rees, D., T. J. Fuller-Rowell, A. Lyons, T. L. Killeen, and P. B. Hays, Stable and Rugged Etalon for the Dynamics Explorer Fabry-Perot Interferometer: I Design and Construction, Applied Optics, 21, 3896-3902, 1982.

Rees, D. and A. H. Greenaway, An Optical Device for Measuring Vector Winds. I. General Principle, Applied Optics, 22, 1078-1083, 1983.

Rees, D., T. J. Fuller-Rowell, R. Gordon, T. L. Killeen, P. B. Hays, L. E. Wharton, and N. W. Spencer, A comparison of the wind observations from the Dynamics Explorer satellite with the predictions of a global time-dependent model, Planet. Space Sci., 31, 1299-1314, 1983.

Rees, D., N. Lloyd, P. J. Charlton, M. Carlson, J. Murdin, and I. Haggstrom, Comparison of plasma flow and thermospheric circulation over northern Scandinavia using EISCAT and a Fabry-Perot interferometer, J. Atmos. Terr. Phys., 46, 545-564, 1984.

Rees, D., Balloon-Based Interferometric techniques, Proceedings of the NASA symposium on Global wind Measurements, edited by W. E. Baker and R. J. Curran, p. 109, Deepak Publishing, Hampton, VA, 1985.

Rees, D., R. Gordon, T. J. Fuller-Rowell, M. F. Smith, G. R. Carignan, T. L. Killeen, P. B. Hays, and N. W. SPENCER, The composition, structure, temperature and dynamics of the upper thermosphere in the polar regions during October to December 1981, Planet. Space Sci., 33, 617-666, 1985.

Rees, D., T. J. Fuller-Rowell, R. Gordon, M. F. Smith, J. P. Heppner, N. C. Maynard, N. W. Spencer, L. E. Wharton, P. B. Hays, and T. L. Killeen, A theoretical and empirical study of the response of the high-latitude thermosphere to the sense of the "Y" component of the interplanetary magnetic field, Planet. Space Sci., 34, 1-40, 1986.

ReEs, D. and T. J. Fuller-Rowell, Comparison of theoretical models and observations of the thermosphere and ionosphere during extremely disturbed geomagnetic conditions during the last solar cycle, $A d v$. Space Res., 7, 827-838, 1987a, Pergamon.

Rees, D. and T. J. Fuller-Rowell, A Theoretical Thermosphere Model for CIRA, Adv. Space Res., 7, 10185-10197, 1987b. 
ReEs, D. and T. J. Fuller-Rowell, The response of the thermosphere and ionosphere to magnetospheric forcing, Phil. Trans. R. Soc. Lond. A, 328, 139-171, 1989.

Rees, D., I. MCWhirter, A. Aruliah, and S. Batten, Upper Atmospheric Wind and Temperature Measurements using Imaging Fabry-Perot Interferometers, WITS Handbook, edited by C. H. Liu, Vol. 2, 188-223, 1989.

Rees, D., A. Aruliah, T. J. Fuller-Rowell, V. B. Wickwar, and R. J. Sica, Winds in the Upper Mesosphere at Mid-Latitude: First Results using an Imaging Fabry-Perot Interferometer, Geophys. Res. Lett., Vol. 17, No. 9, 1259-1262, 1990.

REES, D., unpublished data, 1990.

Rees, M. H., D. Lummerzheim, R. G. Roble, J. D. Winningham, J. D. Craven, and L. A. Frank, Auroral Energy Deposition Rate, Characteristic Electron Energy, and Ionospheric Parameters Derived from Dynamics Explorer 1 Images, J. Geophys. Res., Vol. 93, 12841-12860, 1987.

Richmond, A. D. and Y. KAMIDE, Mapping electrodynamic features of the high-latitude ionosphere from localized observations: Technique, J. Geophys. Res., 93, 5741-5759, 1988.

Rishbeth, H., Thermospheric winds and the F-region, J. Atmos. Terr. Phys., 34, 1-47, 1972.

Roble, R. G., R. E. Dickinson, E. C. Ridley, B. A. Emery, P. B. Hays, T. L. Killeen, and N. W. Spencer, The high latitude circulation and temperature structure of the thermosphere near solstice, Planet. Space Sci., 31, 1479, 1983.

Roble, R. G., B. A. Emery, R. E. Dickinson, E. C. Ridley, T. L. Killeen, P. B. Hays, G. R. Carignan, and N. W. SPENCER, Thermospheric circulation, temperature, and compositional structure of the southern hemisphere polar cap during October-November 1981, J. Geophys. Res., 89, 9057-9068, 1984.

RoElof, E. C., Energetic neutral atom image of a storm-time ring current, Geophys. Res. Lett. 14, 652, 1987.

SCHunk, R. W. (1989), Magnetosphere-Ionosphere-Thermosphere Coupling Processes, STEP Symposium ESPOO, 1988.

SCHUNK, R. W. (1991), Model studies of ionosphere-thermosphere coupling phenomena on both large and small spatial scales and from high to low altitudes, These Proceedings, STEP Symposium, The Hague, 1990.

Shepherd, G. G., W. A. Gault, R. A. Koehler, J. C. McConnell, K. V. Paulson, E. J. Llewellyn, C. D. Anger, L. L. Cogger, J. W. Haslett, D. R. Moorcroft, and R. L. Gattinger, Optical Doppler Imaging of the Aurora Borealis, Geophys. Res. Lett., 11, 1003-1006, 1984.

SMITH, R. W. and P. J. SweEnEy, Winds in the thermosphere of the northern winter polar cap, Nature, 284, 437-438, 1978.

Spencer, N. W., L. E. Wharton, H. B. Nieman, G. R. Carignan, and J. C. Maurer, The Dynamics Explorer wind and temperature spectrometer, Space Sci. Instrum., 5, 417-2428, 1981.

Thuiller, G., C. Lathuillere, M. Herse, C. Senior, W. Kofman, M. L. Duboin, D. Alcayde, and J. FONTANARI, Coordinated EISCAT-MIKADO Interferometer Measurements of Neutral Winds and Temperatures in the $E$ and $F$ Regions, J. Atmos. Terr. Phys., 52, 6-8, 625-636, 1990.

THUiLleR, G., private communication, 1990.

Tinsley, B. A., Y. Sahai, M. A. Biondi, and J. W. Meriwether, Equatorial particle precipitation during geomagnetic storms and relationship to equatorial thermospheric heating, J. Geophys. Res., 93, 270-276, 1988.

Wickwar, V. B., J. W. Meriwether, Jr., P. B. Hays, and A. F. Nagy, The meridional thermospheric neutral wind measured by radar and optical techniques in the auroral region, J. Geophys. Res., 89, 1098710998,1984

Wickwar, V. B., R. M. Johnson, R. G. Roble, and J. G. Luhmann, Lower-thermospheric winds at high latitude: Chatanika radar observations, Annales Geophysicae, 5A, (6), 383-404, 1987.

Winser, K. J., A. D. Farmer, D. ReEs, and A. Aruliah, Ion-neutral dynamics in the high latitude ionosphere: first results from the INDI experiment. J. Atmos. Terr. Phys., Vol. 50, No. 4/5, 369$377,1988$. 